\title{
CUESTIONES SOBRE EL DERECHO AL TRABAJO DERIVADAS DE LA REFORMA LABORAL DE 2012. PERSPECTIVA CONSTITUCIONAL
}

\author{
RAFAEL NARANJO DE LA CRUZ
}


SUMARIO

1. INTRODUCCIÓN. 2. DERECHO AL TRABAJO Y LIBERTAD DE EMPRESA. 3. DERECHO AL TRABAJO Y LIBRE EXTINCIÓN DE LA RELACIÓN LABORAL DURANTE SU PRIMER AÑO: 3.1. Planteamiento inicial. 3.2. Sobre la constitucionalidad del periodo de prueba de un año de duración. 3.3. La concesión al empresario de la libre potestad de resolución del contrato durante su primer año de vigencia. 4. ESTÍ́MULO A LA CONTRATACIÓN DE PERCEPTORES DE LA PRESTACIÓN CONTRIBUTIVA POR DESEMPLEO E IGUALDAD EN EL ACCESO A UN PUESTO DE TRABAJO. 5. ESTUDIO CRÍTICO DEL RÉGIMEN LEGAL DEL DESPIDO IMPROCEDENTE Y LOS SALARIOS DE TRAMITACIÓN DESDE UNA PERSPECTIVA CONSTITUCIONAL: 5.1. Planteamiento inicial. 5.2. El despido improcedente: un análisis constitucional 5.3. Constitución y supresión de los salarios de tramitación. 6. EL CONTROL JUDICIAL DE LAS CAUSAS DE DESPIDO COLECTIVO. 7. REFLEXIÓN FINAL. 


\title{
CUESTIONES SOBRE EL DERECHO AL TRABAJO DERIVADAS DE LA REFORMA LABORAL DE 2012. PERSPECTIVA CONSTITUCIONAL ${ }^{1}$
}

\author{
RAFAEL NARANJO DE LA CRUZ \\ Profesor Titular de Derecho Constitucional \\ Universidad de Málaga
}

\section{INTRODUCCIÓN}

El Derecho del Trabajo es el escenario, por su propia naturaleza, del conflicto que permanentemente envuelve la relación entre distintos derechos fundamentales y principios constitucionales. Así, en la relación laboral interactúan los derechos constitucionales del trabajador, sean o no específicos de este ámbito, con los intereses del empresario, algunos de ellos cubiertos por su libertad de empresa (art. $38 \mathrm{CE}$ ) o su derecho a la propiedad (art. $33 \mathrm{CE}$ ). Como sucede en tantos otros ámbitos, la tensión entre estos bienes tiende a recrudecerse y a ponerse de manifiesto en mayor medida en situaciones de crisis, como la que actualmente vivimos en el plano económico. Un interesante ejemplo lo encontramos en la Ley 3/2012, de 6 de julio, de medidas urgentes de reforma del mercado laboral y en el debate que en torno a ella se ha suscitado en el plano doctrinal e institucional ${ }^{2}$.

${ }^{1}$ Este artículo es una reelaboración y desarrollo de uno de los aspectos abordados en la ponencia que con el título de «Las cuestiones de inconstitucionalidad sobre la reforma laboral» presenté en el XI Congreso de la Asociación de Constitucionalistas de España, que se celebró en Barcelona los días 21 y 22 de febrero de 2013.

${ }^{2}$ En este sentido, cabe destacar que la norma ha sido objeto de dos recursos de inconstitucionalidad: uno presentado conjuntamente por diputados del Grupo Parlamentario Socialista y del Grupo Parlamentario de IU; ICV-EUiA; CHA: La Izquierda Plural (en adelante, «el recurso de los grupos parlamentarios») y otro interpuesto por el Parlamento de Navarra. El TC ya ha 
El objeto de este trabajo es, precisamente, analizar, desde una perspectiva constitucional, los efectos que sobre el derecho al trabajo del art. 35.1 CE tienen algunas de las medidas adoptadas por la Ley citada. Concretamente, el régimen jurídico del contrato por tiempo indefinido de apoyo a emprendedores permite plantearse si cabe en nuestro ordenamiento un período de prueba de un año o, incluso, como veremos, si se puede conceder al empresario una potestad incondicionada de despido del trabajador durante el primer año de contrato. Esta misma figura contractual nos llevará a estudiar si se puede fomentar, mediante deducciones en la cuota íntegra del impuesto de sociedades, la contratación de desempleados beneficiarios de una prestación contributiva por desempleo. Por otra parte, las dudas surgidas sobre la supresión de los salarios de tramitación en los casos de despido improcedente en los que el empresario opta por la indemnización nos llevarán a adentrarnos en la conformidad a la Constitución del régimen jurídico vigente de esta figura extintiva. Por último, abordaremos si la plasmación de la declarada intención del legislador de acotar la función judicial de control de la causa de los despidos colectivos en el art. 51 del Estatuto de los Trabajadores (en adelante, ET) ha superado los márgenes permitidos por la Norma Fundamental.

Antes de centrarnos en las cuestiones citadas conviene, sin embargo, exponer de manera resumida los términos generales que definen la relación entre derecho del trabajo y libertad de empresa, ya que ellos condicionan decisivamente los resultados que alcanzaremos.

\section{DERECHO AL TRABAJO Y LIBERTAD DE EMPRESA}

El TC ha distinguido, en el derecho al trabajo del art. 35.1 CE, las siguientes manifestaciones ${ }^{3}$ :

a. Derecho al trabajo como libertad de trabajar (STC 22/1981, f.j. 5).

b. «(I)gual derecho de todos a un determinado puesto de trabajo si se cumplen los requisitos necesarios de capacitación»(STC 22/1981, f.j. 8).

inadmitido hasta el momento dos cuestiones de inconstitucionalidad sobre la reforma laboral: una presentada por el Juzgado de lo Social número 30 de Madrid, mediante Auto de 16 de abril de 2012 y otra por el Juzgado de lo Social número 34 de Madrid, por Auto de 11 de abril de 2013 (AATC 96/2013, de 7 de mayo y de 12 de febrero de 2014). La reforma laboral ha sido objeto también de dos dictámenes del Consell de Garanties Estatutàries de Catalunya, concretamente, los dictámenes 5/2012, de 3 de abril y 10/2012, de 22 de agosto.

${ }^{3}$ Las características de este artículo no permiten realizar un estudio en profundidad de la naturaleza y contenidos del derecho al trabajo. Al respecto, puede verse SASTRE IBARRECHE, R. (1996). El derecho al trabajo, Madrid, Trotta, 1996. 
c. «(D)erecho a la continuidad o estabilidad en el empleo, es decir, a no ser despedidos si no existe justa causa» (STC 22/1981, f.j. 8).

d. Derecho a «la ocupación real y efectiva del trabajador» (ATC 246/2003, f.j. 2).

A lo largo de este estudio nos ocuparemos fundamentalmente de la tercera de las vertientes citadas, esto es, derecho al trabajo como derecho a la continuidad o estabilidad en el empleo. En este momento resulta, sin embargo, necesaria una aclaración: cuando el TC concreta esta manifestación en el derecho a no ser despedido sin justa causa está realizando una interpretación injustificadamente restrictiva del derecho al trabajo, que parece operar únicamente frente a una modalidad concreta de extinción de la relación laboral que es el despido. A nuestro juicio, esta vertiente del derecho al trabajo como derecho a la continuidad o estabilidad en el empleo protege al trabajador frente a cualquier forma de extinción de la relación laboral, pueda ser calificada técnicamente de despido o no ${ }^{4}$. Así, por ejemplo, la fijación por ley o mediante convenio colectivo de una edad de jubilación forzosa afecta a todos en el aspecto del derecho al trabajo que representa la libertad de trabajar, tal y como hemos visto que afirma la STC 22/1981, en la medida en que a partir de su cumplimiento tal libertad ya no existe. Sin embargo, cuando esta medida se proyecta específicamente sobre el trabajador que ocupa en ese momento un empleo concreto, obligándole con ello a abandonarlo, a la anterior manifestación se une la del derecho a la continuidad o estabilidad en el empleo.

El mismo análisis cabe hacer de la extinción del contrato a instancias del empresario durante el período de prueba. En la concepción que de esta figura parece manejar el TC, nos encontraríamos ante un supuesto de resolución del contrato de trabajo; «un sistema extintivo diferente al del despido, cuyas reglas y principios no le son aplicables», lo que se manifiesta, por ejemplo, en la falta de necesidad de motivación (STC 94/1984, f.j. 3). En definitiva, si, por un lado, la extinción del contrato de trabajo durante el período de prueba no es un supuesto de despido, y, por otro, como hemos visto, el derecho al trabajo protege únicamente frente al despido sin causa, la conclusión debería ser que el trabajador en pruebas no se encuentra protegido en ningún caso por el derecho del art. 35.1 CE.

${ }^{4}$ Este planteamiento puede verse también en CRUZ VILLALÓN, J. (2012). «Los cambios en materia de extinciones individuales en la reforma laboral de 2012». Relaciones Laborales, núm. 23, Sección Monografías, p. 3. Citado por su versión en pdf en la leydigital.es. Última visita el 08/01/2013. En este mismo sentido, se ha afirmado que «(l)a causalidad del despido no constituye un problema exclusivo de éste, al predicarse la causalidad de la extinción del contrato, en general» (SASTRE IBARRECHE, op. cit., p. 242. Cursiva también en el original). 
Como veremos, sin embargo, en el próximo epígrafe, esta figura puede ser explicada mejor de otra manera en términos constitucionales.

Por otro lado, la libertad de empresa del art. 38 CE garantiza, en general, el inicio y el mantenimiento de la actividad empresarial «en libertad», lo que supone «el reconocimiento a los particulares de una libertad de decisión no sólo para crear empresas y, por tanto, para actuar en el mercado, sino también para establecer los propios objetivos de la empresa y dirigir y planificar su actividad en atención a sus recursos y a las condiciones del propio mercado» (SSTC 225/1993, f.j. 3.b); 112/2006, f.j. 8; ATC 71/2008, f.j. 7). En otro lugar, el alto Tribunal ha reconocido como imprescindibles tres vertientes del derecho del art. $38 \mathrm{CE}$ : la libertad de contratación, la libertad de inversión y la libertad de organización (STC 112/2006, f.j. 13) $)^{5}$. Esta libertad de contratación se proyecta claramente en material laboral, en la medida en que a ella puede reconducirse la libertad del empresario para seleccionar a sus trabajadores, si bien debe tenerse en cuenta que, como todo derecho fundamental, puede ser limitado [STC 147/1986, f.j. 4 b)]. La libertad de empresa del art. 38 CE también da cobertura constitucional al ejercicio de poderes y facultades para la gestión de la empresa, incluidas medidas referentes a la llamada gestión de personal que afectan al desarrollo del contrato de trabajo (STC 208/1993, f.j. 4; 107/2000, f.j. 7; 238/2005, f.j. 4) ${ }^{6}$.

Ahora bien, el que la libertad de empresa recoja en su ámbito de delimitación estas manifestaciones no implica que el titular de la empresa disponga de un poder omnímodo en cada uno de los ámbitos de los que se trata ${ }^{7}$. La adecuada

5 Los pronunciamientos doctrinales sobre el contenido de la libertad de empresa son muy abundantes. Por todos, pueden verse DE JUAN ASENJO, O. (1984). La Constitución económica española. Iniciativa económica pública «versus» iniciativa económica privada en la Constitución española de 1978, Madrid, Centro de Estudios Constitucionales, especialmente pp. 154-155; DE GISPERT PASTOR, M. ${ }^{a}$ T. (1989). «La noción de empresa en la Constitución Española», en AA. VV., La empresa en la Constitución Española, Pamplona, Aranzadi, pp. 44-45; o RUIZ-RICO RUIZ, G. (1995). «La libertad de empresa en la Constitución Económica Española: especial referencia al principio de la libre competencia». Revista de Derecho Mercantil, núm. 215, pp. 233 y ss.

${ }^{6}$ Sobre los contenidos laborales de la libertad de empresa, por todos, DURÁN LÓPEZ, F. (2005). «Contenidos laborales del derecho constitucional a la libertad de empresa», en PÉREZ DE LOS COBOS ORIHUEL, F. (dir.), Libertad de empresa y relaciones laborales en España, Madrid, Instituto de Estudios Económicos, especialmente p. 59.

7 Sobre la necesidad de hallar un equilibrio entre la libertad de empresa y el derecho al trabajo, por todos, RODRÍGUEZ-PIÑERO Y BRAVO-FERRER, M. (1997). «Derecho, trabajo y despido». Relaciones Laborales, núm. 1, tomo 1, p. 5 (citado por la versión electrónica en pdf, obtenida en laleydigital.es, última visita 22/04/2013); SAGARDOY BENGOECHEA, J. A. (2003). «Los derechos constitucionales del empresario», en SEMPERE NAVARRO, A. V. (dir.), El modelo social en la Constitución Española de 1978, Madrid, Ministerio de Trabajo y Asuntos Sociales, p. 361. Como afirma la STC 192/2003, «(d)esde sus orígenes, la legislación sobre el contrato 
interpretación del derecho del art. 38 CE y su emplazamiento en el conjunto del texto constitucional imposibilitan una lectura del precepto constitucional que otorgue al titular de la empresa carta blanca para iniciar la actividad que desee, en los términos y condiciones que estime oportunos. La propia configuración constitucional de la libertad de empresa apunta a una cierta debilitación de su contenido, al sujetar su protección a «las exigencias de la economía general y, en su caso, de la planificación». Entre las exigencia de la economía general a las que se refiere el art. $38 \mathrm{CE}$ «hay que incluir las que pueden imponerse en virtud de determinados bienes o principios constitucionalmente protegidos», como sería el caso de los incluidos en los arts. 40, 128.1 o 130.1 CE (STC 37/1987, f.j. 5) ${ }^{8}$. Al mismo tiempo, dada la relación que mantiene con el derecho a la propiedad (art. $33 \mathrm{CE}$ ), la libertad de empresa se halla expuesta a los condicionantes que pudieran derivarse de su función social ${ }^{9}$. Finalmente, la actividad empresarial constituye, por su propia esencia, el punto donde se cruzan numerosos bienes, derechos e intereses, algunos de los cuales poseen relevancia constitucional. De la interacción de todos ellos resulta la imposición de importantes limitaciones al poder empresarial ${ }^{10}$.

Por lo que respecta específicamente a la interacción entre libertad de empresa y derecho al trabajo, el TC ha indicado que

«tanto exigencias constitucionales, como compromisos internacionales, hacen que rija entre nosotros el principio general de la limitación legal del despido,

de trabajo viene siendo una legislación limitativa del poder empresarial que, a causa de ella, dejó de ser absoluto» (f.j. 6).

${ }^{8}$ Para el TC el contenido esencial de la libertad de empresa ha de ser compatible en todo caso con el principio declarado en el art. 128.1 y con las habilitaciones específicas que al legislador confieren tanto el apartado segundo de este mismo artículo como el art. 131.1 CE (STC 37/1981, f.j. 2). Sobre la necesidad de interpretar el art. 38 CE poniéndolo en relación con los arts. 128 y 131 CE, véase las SSTC 96/2002, f.j. 11; 225/1993, f.j. 3 B).

9 Como señala el TC acerca de la propiedad agrícola, en unos términos extensibles a todo tipo de propiedad, «no tendría sentido —antes bien, sería contradictorio- que, pudiendo recaer sobre el propietario, no fueran lícitas respecto del empresario, coincida o no con aquél» las restricciones o deberes impuestos sobre la base de la función social de la propiedad. Por ello, concluye el alto Tribunal que «las limitaciones a la actividad empresarial agrícola son (...) indisociables de las limitaciones a las facultades de uso y disfrute de la propiedad rústica, determinadas por la función social de esta última (STC 37/1987, f.j. 5). En este mismo sentido, STC 89/1994, f.j. 6. Sobre la posibilidad de deducir límites y restricciones para la libertad de empresa de la función social, STC 227/1993, f.j. 4 e).

${ }^{10}$ Por lo que al ámbito de la relación laboral se refiere, esta exposición de los poderes del empresario a límites encuentra por lo demás un claro reflejo en el texto constitucional, en la medida en que este prevé que su desarrollo se ajuste a lo establecido en un estatuto de los trabajadores, que tiene que ser aprobado por ley (art. 35.2 CE) y a los convenios que resulten del ejercicio del derecho a la negociación colectiva entre los representantes de los trabajadores y empresarios (art. 37.1 CE). 
así como su sujeción para su licitud a condiciones de fondo y de forma. Ello no quiere decir que, como poder empresarial, la facultad de despido no se enmarque dentro de los poderes que el ordenamiento concede al empresario para la gestión de su empresa y que, por ello, su regulación no haya de tener en cuenta también las exigencias derivadas del reconocimiento constitucional de la libertad de empresa y de la defensa de la productividad, pero lo que resulta claro es que no puede deducirse de esa libertad de empresa ni una absoluta libertad contractual, ni tampoco un principio de libertad ad nutum de despido, dada la necesaria concordancia que debe establecerse entre los arts. 35.1 y $38 \mathrm{CE}$ y, sobre todo, el principio de Estado social y democrático de Derecho. No debe olvidarse que hemos venido señalando desde nuestra STC 22/1981, de 2 de julio, FJ 8, que, en su vertiente individual, el derecho al trabajo (art. 35.1 CE) se concreta en el "derecho a la continuidad o estabilidad en el empleo, es decir, en el derecho a no ser despedido sin justa causa”» (STC 192/2003, f.j. 4) ${ }^{11}$.

De este fragmento se puede deducir que la facultad de despido se encuentra entre los poderes que la libertad de empresa concede a su titular. Forma parte, por tanto, de la delimitación del derecho del art. 38 CE. Sin embargo, este derecho protege tal facultad únicamente prima facie, esto es, en principio. Al quedar incluido en el derecho al trabajo el derecho a la estabilidad en el empleo, la protección constitucional de la facultad de despido del empresario decae, como vimos con anterioridad, cuando es ejercida sin justa causa. La exigencia de justa causa opera así, en tanto que límite a la libertad de empresa, como condición sine qua non de la constitucionalidad del despido. Dicho de otra forma: el despido libre no tiene cabida en nuestro texto constitucional ${ }^{12}$.

${ }^{11}$ Contra la consideración del poder de despido como parte del contenido esencial de la libertad de empresa BAYLOS, A. y PÉREZ REY, J. (2009). El despido o la violencia del poder privado, Madrid, Trotta, nota 16, pp. 96 y 97.

${ }^{12} \mathrm{La}$ inconstitucionalidad del despido libre ha sido señalada abundantemente por la doctrina. Entre otros, en este sentido, ALARCÓN CARACUEL, M. R. (1979). «Derecho al trabajo, libertad profesional y deber de trabajar». Revista de Política Social, núm. 121, p. 29; RODRÍGUEZ-PIÑERO, M., (1980). «Presentación: el trabajo en la Constitución», en, del mismo autor (coord.), Los trabajadores y la Constitución, Madrid, Sociedad de Estudios Laborales, pp. 25-26; BLASCO PELLICER, A. (2003), «La extinción del contrato de trabajo en el sistema constitucional de relaciones laborales», en SEMPERE NAVARRO (dir.), El modelo ..., cit., p. 456; BAYLOS/ PÉREZ REY, op. cit., p. 67; MARTÍNEZ ABASCAL, V. A. (2003). «Derecho al trabajo y políticas de empleo», en SEMPERE NAVARRO (dir.), El modelo..., p. 1305; RODRÍGUEZPIÑERO y BRAVO-FERRER habla de una «libertad de despido condicionada en su licitud a su justificación, exigencia que actúa como límite de los poderes empresariales» («Derecho..., cit., p. 8). DE JUAN ASENJO, sin embargo, rechaza que el art. $35.1 \mathrm{CE}$ ofrezca un fundamento constitucional sólido frente al despido ad nutum y entiende posible un futuro pronunciamiento 
A su vez, podrá considerarse justa causa a estos efectos la necesidad de lograr la consecución de un objetivo libremente definido por el empresario en el ejercicio de su derecho del art. $38 \mathrm{CE}$, o exigencias derivadas de la organización y desarrollo de la actividad productiva amparadas por los arts. 38 o 33 CE. Al respecto no se puede descartar que desempeñe un importante papel el establecimiento como objetivo de la empresa de la consecución de un determinado beneficio, toda vez que, como se deduce de la jurisprudencia constitucional, el ánimo de lucro constituye un elemento esencial de la empresa privada amparada en el art. $38 \mathrm{CE}^{13}$. Lo que queda radicalmente excluido es que la facultad de despido, aun integrando el contenido de la libertad de empresa, pueda actuar en sí misma como único fundamento, incondicionado, de la decisión extintiva. Estaríamos, en tal caso, ante un despido arbitrario, contrario al derecho al trabajo del art. 35 CE.

La valoración de la importancia constitucional del derecho a la estabilidad o continuidad en el empleo, y por tanto del acto empresarial extintivo de la relación laboral, no ha de quedarse, sin embargo, en el derecho constitucional del art. 35.1 CE. En ella intervienen otros principios constitucionales, que se ven afectados aun de manera indirecta, como tendremos ocasión de comprobar más adelante.

Una vez presentados a grandes rasgos los elementos jurídicos que protagonizan, en un modo más destacado, el objeto de estudio que nos ocupa, dedicaremos los siguientes epígrafes a analizar detenidamente los aspectos de la reforma laboral de 2012 a los que hicimos referencia en la introducción de este trabajo.

\section{DERECHO AL TRABAJO Y LIBRE EXTINCIÓN DE LA RELACIÓN LABORAL DURANTE SU PRIMER AÑO}

\subsection{Planteamiento inicial}

Una de las medidas estrella de la Ley 3/2012 fue la contenida en el, por ella misma denominado, «contrato de trabajo por tiempo indefinido de apoyo a los emprendedores» (art. 4 de la Ley). En el apartado tercero del citado precepto

del TC a favor de la teoría económica liberal, favorable a la flexibilización del despido (op. cit., pp. 158-159).

13 STC 49/1988, f.j. 2. La definición de la empresa garantizada en el art. 38 CE en torno a la finalidad de lucro, lleva al TC a afirmar que «sería incompatible con tal garantía constitucional la genérica y absoluta exclusión legal de tal libertad empresarial — movida por la búsqueda del beneficio- en todo un determinado ámbito de la actividad económica, de no venir dada tal exclusión por lo dispuesto en el segundo inciso del art. 128.2 CE o en atención a la previa caracterización como ilícito del tráfico o actividad en cuestión» (STC 84/1993, f.j. 2; ATC 71/2008, f.j. 7). 
legal se dispone que «(e)l régimen jurídico del contrato y los derechos y obligaciones que de él se deriven se regirán, con carácter general, por lo dispuesto en el Texto Refundido de la Ley del Estatuto de los Trabajadores, aprobado por Real Decreto Legislativo 1/1995, de 24 de marzo, y en los convenios colectivos para los contratos por tiempo indefinido, con la única excepción de la duración del periodo de prueba a que se refiere el artículo 14 del Estatuto de los Trabajadores, que será de un año en todo caso» (la cursiva es nuestra). En este apartado no pretendemos desarrollar un análisis completo de las peculiaridades de esta nueva modalidad contractual, sino tan solo estudiar la constitucionalidad de tan dilatado período de pruebas, que ha sido cuestionada tanto por los recursos de inconstitucionalidad presentados contra la Ley como desde un sector de la doctrina laboralista ${ }^{14}$.

Antes de adentrarnos en esta cuestión conviene realizar una precisión. Resulta frecuente el recurso por la doctrina laboralista al art. 10.2 CE para justificar, en distintos aspectos, una interpretación del derecho al trabajo de acuerdo con normas internacionales, muy especialmente las contenidas en el Convenio 158 OIT. Por lo que aquí respecta, interesa su art. 4, que dispone que «(n)o se pondrá término a la relación de trabajo de un trabajador a menos que exista para ello una causa justificada relacionada con su capacidad o su conducta o basada en las necesidades de funcionamiento de la empresa, establecimiento o servicio» (art. 4). El Convenio citado permite, sin embargo, a los Estados parte excluir de sus disposiciones a «los trabajadores que efectúen un período de prueba o que no tengan el tiempo de servicios exigido, siempre que en uno u otro caso la duración se haya fijado de antemano y sea razonable» [art. 2.2.b)], lo que ha llevado a abrir un debate sobre, por un lado, si el art. 4 de la Ley ha de ser considerado a estos efectos como periodo de prueba o como tiempo de servicios exigido para disfrutar de protección frente al despido, y por otro, sobre la razonabilidad del plazo de un año fijado legalmente ${ }^{15}$.

${ }^{14}$ Véanse el fundamento jurídico 7 del recurso presentado por los grupos parlamentarios y el fundamento de Derecho tercero del recurso presentado por el Parlamento de Navarra.

15 Un análisis detenido acerca de los motivos por los que no puede considerarse que la figura española entre en las excepciones dispuestas por el art. 2.2.b) del Convenio 158 OIT, en BAZ RODRÍGUEZ, J. (2012). «El contrato de trabajo indefinido de apoyo a los emprendedores. Análisis crítico de una apuesta por la «flexi-inseguridad». Revista de Derecho Social, núm. 59, pp. 98-102. Sostienen la contradicción del período de prueba de un año con el Convenio 158 OIT, entre otros, BAYLOS GRAU, A. (2012). «El sentido general de la reforma: la ruptura de los equilibrios organizativos y colectivos y la exaltación del poder privado del empresario». Revista de Derecho Social, núm. 57, p. 13; PÉREZ REY, J. (2012). «El contrato de apoyo a los emprendedores: una nueva vuelta de tuerca a la precariedad como fórmula de fomento del empleo». Revista de Derecho Social, núm. 57, p. 60; MORENO VIDA, M. ${ }^{a}$ N. (2012). «Novedades en materia de modalidades contractuales: contrato indefinido para pequeñas empresas, trabajo a tiempo parcial y trabajo a distancia». Temas Laborales. Revista Andaluza de Trabajo y Bienestar Social, núm. 115, 
A nuestro juicio, sin embargo, este examen es prescindible a los fines de nuestro trabajo. El hecho de que el tratado permita al Estado realizar, como hemos visto, ciertas exclusiones, no exime al legislador nacional de ajustarse a las exigencias que, en el plano interno, deriven de su Constitución. Esto es especialmente relevante cuando, como es el caso, la norma constitucional, tal y como es interpretada por el TC, garantiza al derecho un nivel de protección no superado por la norma internacional examinada. En tales condiciones, el recurso a ella no debe ser determinante desde un punto de vista constitucional ${ }^{16}$.

\subsection{Sobre la constitucionalidad del periodo de prueba de un año de duración}

La relevancia constitucional de la duración del periodo de prueba resulta del hecho de que, durante el mismo, el trabajador carece de los derechos «derivados de la resolución de la relación laboral, que podrá producirse a instancia de cualquiera de las partes durante su transcurso» (art. 14.2 ET). Esto implica, por lo que al objeto de nuestro estudio respecta, que la relación laboral puede quedar resuelta a instancias del empresario sin necesidad de invocar una causa que lo justifique, sin derecho del trabajador a recibir una indemnización y sin sujetarse a requisito alguno de fondo o de forma. El control judicial queda limitado, por lo que aquí interesa, básicamente a los supuestos de discriminación o lesión de derechos fundamentales ${ }^{17}$. Nos encontramos, por tanto, como vimos con anterioridad, ante un

Monográfico sobre la Reforma Laboral de 2012, p. 200; ESCUDERO RODRÍGUEZ, R. (2012). «El nuevo contrato de trabajo por tiempo indefinido de apoyo a los emprendedores: régimen sustantivo, incentivos fiscales y bonificaciones en las cuotas de la Seguridad Social». Actum Social, núm. 61, p. 9, versión electrónica; SUÁREZ CORUJO, B. (2012). «Ruptura laboral y posibles aspectos inconstitucionales». El Cronista del Estado Social y Democrático de Derecho, núm. 31, p. 32; RAMOS MORAGUES, F. (2013). «El contrato de apoyo a los emprendedores como medida de fomento del empleo». Revista Española de Derecho del Trabajo, núm. 157, pp. 214-215. En sentido contrario, GÓMEZ ABELLEIRA, J. (2012). «Medidas para favorecer el empleo estable: el contrato de apoyo a los emprendedores y la recuperación de la conversión en indefinido por reiteración de contratos temporales», en GARCÍA-PERROTE ESCARTÍN, I. y MERCADER UGUINA, J. R. (dirs.), La regulación del Mercado Laboral. Un análisis de la Ley 3/2012 y de los aspectos laborales del Real Decreto-ley 20/2012, Valladolid, Lex Nova, pp. 75-76 y 79; SÁNCHEZ-URÁN AZAÑA, Y. (2012). «Apoyo al empleo estable y modalidades de contratación», en MONTOYA MELGAR, A. y GARCÍA MURCIA, J. (dirs.), Comentario a la reforma laboral de 2012, Cizur Menor (Navarra), Civitas/Thomson Reuters, p. 71.

${ }^{16}$ Sobre el argumento de la diferencia de estándares de protección en el orden internacional e interno puede verse, en otro contexto, NARANJO DE LA CRUZ, R. (2000). Los límites de los derechos fundamentales en las relaciones entre particulares: la buena fe, Madrid, Centro de Estudios Políticos y Constitucionales/Boletín Oficial del Estado, pp. 392 y ss.

17 Véase en este sentido la doctrina de las SSTC 94/1984, 166/1988 o 71/1993. 
límite al derecho constitucional del art. 35.1 CE, en su vertiente de derecho a la continuidad o estabilidad en el empleo, pues este derecho se ve truncado por toda decisión resolutoria del empresario no sujeta a la exigencia de justa causa ${ }^{18}$.

El reconocimiento de la posibilidad de concertar un periodo de prueba se encuentra amparado, sin embargo, por la libertad de empresa del art. $38 \mathrm{CE}$, en la medida en que con él se satisface una necesidad básica del empresario, que no es otra que conocer las aptitudes reales del trabajador para el desempeño de las funciones que constituyen el objeto del contrato y constatar el modo en que aquel se inserta en la organización productiva que es la empresa ${ }^{19}$. Por este motivo, el Estatuto de los Trabajadores declara nulo el pacto que establezca un período de prueba cuando el trabajador haya ya desempeñado las mismas funciones con anterioridad en la empresa, bajo cualquier modalidad de contratación. En tal caso, debe entenderse desde una perspectiva constitucional que no concurre el fin que justifica su existencia, toda vez que las cualidades del trabajador han sido ya contrastadas.

Sin embargo, aun reconociendo que el periodo de prueba es un medio adecuado y necesario para satisfacer una necesidad básica para el correcto funcionamiento de la empresa, la concordancia práctica de la libertad de empresa con el derecho al trabajo exige la fijación de límites a su duración que aseguren que la eficacia del derecho al trabajo no se vea en exceso sacrificada ante tal interés ${ }^{20}$. Es por ello que el art. $14 \mathrm{ET}$, en su apartado primero, regula con carácter general los límites temporales del periodo de prueba: «(e)n defecto de pacto en Convenio, la duración del período de prueba no podrá exceder de seis meses para los técnicos titulados, ni de dos meses para los demás trabajadores. En las empresas de menos de veinticinco trabajadores el período de prueba no podrá exceder de tres

18 Se ha puesto esta norma como ejemplo de «descausalización de la resolución contractual» (CRUZ VILLALÓN, «Los cambios...», cit., pp. 3-4). Con base en la STC 6/1984, la doctrina ha rechazado mayoritariamente el carácter discriminatorio de la norma que limita el uso de este contrato de apoyo a emprendedores a las empresas de menos de 50 trabajadores. En este sentido, GÓMEZ ABELLEIRA, op. cit., p. 76; RAMOS MORAGUES, op. cit., pp. 213-214; o PÉREZ REY, op. cit., pp. 54-55. Cuestiona la aplicabilidad de esta sentencia al caso que nos ocupa CAMPS RUIZ, L. M. (2012). «Contratación, formación y empleo en el RDL 3/2012», en BLASCO PELLICER, A. y otros, La reforma laboral en el Real Decreto-Ley 3/2012, Valencia, Tirant lo Blanch, pp. 73-74. Sostiene inicialmente el argumento de la desigualdad, GARCÍA BLASCO, J. (2012). «La contratación laboral en la reforma legal de 2012: entre el estímulo de la contratación indefinida y la preocupación por el empleo». Documentación Laboral. Revista de relaciones laborales, economía y sociología del trabajo, y trabajo autónomo, núms. 95-96, p. 16.

${ }_{19}$ Cfr., en este sentido el recurso de los grupos parlamentarios, pp. 67-68. En la doctrina, GÓMEZ ABELLEIRA, op. cit., p. 74, BAZ RODRÍGUEZ, op. cit., p. 97.

${ }^{20}$ Por todos, SÁNCHEZ-URÁN AZAÑA, op. cit., p. 71. 
meses para los trabajadores que no sean técnicos titulados». La referencia que se hace en este punto a los convenios colectivos tampoco puede ser entendida como una remisión en blanco, de manera que el TS ha declarado la nulidad de la cláusula de un convenio que preveía la injustificada extensión del periodo de prueba a un año ${ }^{21}$.

Precisamente es esta, un año, la duración del periodo de prueba establecida legalmente para los contratos indefinidos de apoyo a emprendedores. Desde el punto de vista de la finalidad de la institución, la previsión de tan extenso periodo resulta, a todas luces, injustificada y desproporcionada ${ }^{22}$. Téngase en cuenta en este sentido, por un lado, que duplica la duración máxima otorgada al periodo de prueba por el art. 14 ET; por otro, que lo hace de manera generalizada, sin distinguir entre trabajadores técnicos titulados y no titulados, de manera que va a estar sujeto a prueba durante un año incluso el trabajador que desempeñe tareas extremadamente sencillas. Ante esta evidencia, no han sido pocas las voces que en la doctrina han sostenido que, en realidad, la figura que se contiene en la Ley 3/2012 no es incardinable en la institución del periodo de prueba ${ }^{23}$.

Que el denominado período de pruebas se aleja, en el contrato de apoyo a los emprendedores, de los fines de la institución regulada en el art. 14 ET es algo que se puede deducir fácilmente del propio texto legal. Así, el art. 4 donde se incluye se encuentra situado en el Capítulo II de la Ley, bajo el epígrafe de «Fomento de la contratación indefinida y otras medidas para favorecer la creación del empleo». En esta idea insiste el propio apartado primero del citado precepto, según el cual «(c)on objeto de facilitar el empleo estable a la vez que se potencia

${ }^{21}$ STS Sala 4. ${ }^{\mathrm{a}}$ de 20 de julio de 2011. En contra del criterio sostenido en esta sentencia, GÓMEZ ABELLEIRA, op. cit., p. 79.

${ }^{22}$ Sobre este argumento, GÓMEZ ABELLEIRA, op. cit., p. 74; SEMPERE NAVARRO, A. V. y MARTÍN JIMÉNEZ, R. (2012). Claves de la Reforma Laboral de 2012. (Estudio del Real Decreto-Ley 3/2012, de 10 de febrero), Cizur Menor (Navarra), Thomson/Aranzadi, p. 183; SUÁREZ CORUJO, op. cit., p. 32; MOLINA NAVARRETE, C. (2012). «Intermediación y políticas activas de empleo: una urgente reforma «que brilla por su ausencia»». Temas Laborales. Revista Andaluza de Trabajo y Bienestar Social, núm. 115, Monográfico sobre la Reforma Laboral de 2012, p. 156; PÉREZ REY, op. cit., p. 59; TOSCANI GIMÉNEZ, D. (2012). «El fomento de la contratación indefinida: el nuevo contrato para emprendedores». Temas Laborales. Revista Andaluza de Trabajo y Bienestar Social, núm. 116, p. 23. En este sentido, además, el recurso de inconstitucionalidad de los grupos parlamentarios, pp. 68 y ss.

${ }_{23}$ Por todos, CRUZ VILLALÓN, J. (2012). «Hacia una nueva concepción de la legislación laboral». Temas Laborales. Revista Andaluza de Trabajo y Bienestar Social, núm. 115, Monográfico sobre la Reforma Laboral de 2012, p. 34 o GORELLI HERNÁNDEZ, J. (2012). «La reforma laboral de 2012 y su impacto en los despidos individuales y otras formas de extinción del contrato de trabajo». Temas Laborales. Revista Andaluza de Trabajo y Bienestar Social, núm. 115, Monográfico sobre la Reforma Laboral de 2012, pp. 309-310. 
la iniciativa empresarial, las empresas que tengan menos de 50 trabajadores podrán concertar el contrato de trabajo de apoyo a los emprendedores que se regula en este artículo». Por último, en el Preámbulo se afirma que la modalidad contractual se crea con la finalidad de «facilitar la contratación de trabajadores por parte de estas empresas, que representan a la mayor parte del tejido productivo de nuestro país y que albergan las diversas fórmulas de organización empresarial que posibilita nuestro ordenamiento jurídico, entre las que cabe destacar el trabajo autónomo y las diversas familias de la economía social».

Denominar «período de prueba» a algo que no comparte los objetivos que contribuyen a conformar el tipo esencial de la institución supone desnaturalizar esta, lo que carecería de relevancia desde un punto de vista constitucional si no fuera por la restricción que, tal y como hemos visto, implica del derecho constitucional al trabajo, desproporcionada por carecer de medida en relación con el objetivo que persigue la institución ${ }^{24}$.

Ahora bien, nuestro análisis no puede detenerse en este punto si no desea quedarse en un plano meramente formal. Desde este punto de vista, la calificación del plazo legalmente dispuesto como «periodo de prueba» podría ser considerada un error de técnica legislativa irrelevante desde una perspectiva constitucional de fondo. La confirmación de que los objetivos que se persiguen con la figura del art. 4.3 de la Ley no son los propios del período de prueba no significa que no persiga otros fines ni que estos carezcan de la relevancia que se exige para cualquier limitación de un derecho constitucional. El examen de su constitucionalidad debe realizarse, pues, a partir de esta nueva referencia, ya que los términos en que se desenvuelve son, como se verá a continuación, absolutamente distintos.

\subsection{La concesión al empresario de la libre potestad de resolución del contrato durante su primer año de vigencia}

Para despejar el camino al nuevo examen a realizar será conveniente reformular los términos del mismo. Por un lado, nos encontramos el derecho al trabajo, en su vertiente de derecho a la continuidad en el empleo. Al otro lado de la balanza se encontraría un doble objetivo: potenciar la iniciativa empresarial y favorecer la creación de puestos de trabajo estables. El primero de ellos consti-

${ }^{24}$ Para MONTOYA MELGAR, sin embargo, sostener la inconstitucionalidad del año de prueba es «un exceso crítico» [MONTOYA MELGAR, A. (2012). «La reforma laboral de 2012: los fines y los medios», en, del mismo autor y GARCÍA MURCIA, J. (dirs.), Comentario a la reforma laboral de 2012, Cizur Menor (Navarra), Civitas/Thomson Reuters, p. 18]. 
tuiría una medida de fomento del ejercicio del derecho a la libertad de empresa del art. $38 \mathrm{CE}$; el segundo se incardina bien en el deber de los poderes públicos de realizar una política orientada al pleno empleo (art. $40 \mathrm{CE})^{25}$. El medio elegido para el logro de estos fines es la creación de un plazo de un año en el que el empresario va a poder despedir libremente al trabajador, sin necesidad de justificar la existencia de una justa causa, de abonar indemnización alguna ni de cumplir ningún otro requisito de fondo o de forma. En definitiva, la nueva modalidad contractual se caracteriza por permitir el despido libre del trabajador durante el primer año de contrato ${ }^{26}$. No puede ser definida de otra forma la extinción de este contrato a instancias del empresario, una vez rechazada la denominación empleada por la Ley ${ }^{27}$. A partir de estos elementos, el examen constitucional de esta figura requiere, ante todo, la aplicación a la restricción experimentada por el derecho al trabajo del test de proporcionalidad ${ }^{28}$ y el examen de su conformidad con el contenido esencial del derecho del art. 35.1 CE.

Una aclaración conviene realizar antes en relación con los fines que persigue la medida analizada. Aunque se ha afirmado que el plazo de un año busca potenciar la iniciativa empresarial o emprendedora, permitiendo a las pequeñas empresas contar con un tiempo razonable para verificar la sostenibilidad económica del puesto de trabajo creado ${ }^{29}$, lo cierto es que, a la vista del desarrollo normativo de la figura contractual, este fin debe entenderse absorbido por el de creación de puestos de trabajo estables. En efecto, este argumento podría estar justificado en los supuestos de inicio de una nueva actividad empresarial, siempre, además, que se incluyeran garantías frente a un eventual uso abusivo en detrimento de la vertiente individual del derecho al trabajo. Difícilmente se puede sostener res-

${ }^{25}$ GÓMEZ ABELLEIRA, op. cit., p. 77.

${ }^{26}$ Para GORELLI HERNÁNDEZ, la fijación del periodo de prueba de un año es paradójica en una modalidad contractual que pretende fomentar el empleo indefinido, con lo que concluye que el objetivo real es facilitar la extinción del contrato de trabajo en estos casos ( «La reforma laboral...», cit., p. 310).

27 Por ello, no tiene razón la tesis que sostiene que «la rescisión libre durante el período de prueba no implicaría una vulneración del art. $35 \mathrm{CE}$ en orden a la prohibición de despido sin causa que de éste se deriva, en tanto en cuanto, la jurisprudencia excepciona del régimen general del despido (señaladamente, de la obligación de justificar la medida extintiva) la rescisión durante dicho período» (RAMOS MORAGUES, op. cit., p. 212).

${ }^{28}$ En opinión de GÓMEZ ABELLAIRA, «puede entrar dentro de un ámbito razonable y necesario de discrecionalidad legislativa modalizar la protección frente a las decisiones extintivas empresariales, en atención a otros intereses (el fomento del empleo) o derechos (el derecho al trabajo en su faceta colectiva) dignos de protección» (op. cit., p. 91).

29 Así, GÓMEZ ABELLEIRA, op. cit., p. 77; SÁNCHEZ-URÁN AZAÑA, op. cit., pp. 56 o 74; GARCÍA BLASCO, op. cit., p. 16. 
pecto de situaciones empresariales ya consolidadas, con un volumen además considerable de personal asalariado. Sin embargo, la definición que hace la Ley 3/2012 del término «emprendedor» se aleja del perfil indicado para incluir a toda empresa con menos de 50 trabajadores, lo que abarca, como su propio Preámbulo reconoce, a más del 99 por ciento de las empresas de nuestro país. Para la mayoría de ellas, el equilibrio entre los intereses constitucionalmente protegidos de la empresa y los de sus trabajadores se logra más bien con el recurso, en los supuestos de no viabilidad de la nueva contratación, a los despidos colectivos o por causas objetivas (arts. 51 y 52 ET), especialmente a la vista de la flexibilización experimentada por sus causas. El problema planteado, por tanto, no es otro que si el fomento de la creación de empleo estable puede justificar la instauración de un plazo de un año en el que se permite el despido libre de los trabajadores contratados bajo esta modalidad, pudiendo ser utilizado el argumento que aquí se aborda, en su caso, como criterio de ponderación junto con el que ofrece el art. $40 \mathrm{CE}$.

Por lo que a la adecuación de la medida se refiere, para el legislador la ausencia de coste de la extinción de la relación laboral durante su primer año de vida impulsaría al empresario a entrar en el mercado laboral. Téngase en cuenta que el criterio de adecuación no exige que el límite logre una definitiva consecución del fin perseguido. Queda satisfecho con tal de que la restricción del derecho constitucional se muestre apta para avanzar en ese sentido, cualquiera sea el grado en el que lo consiga ${ }^{30}$. Como señala el TC, la medida solo podría ser considerada no adecuada, y por tanto, desproporcionada, si «resultara manifiesto que (...) entorpece o, cuando menos, es indiferente desde la perspectiva del cumplimiento de sus fines» (STC 60/2010, f.j. 12).

De este modo, entramos de lleno en un debate difícilmente resoluble con los argumentos meramente técnicos con los que se ha de manejar el principio anali$z^{2}{ }^{31}$. Por ello, es previsible que el alto Tribunal opte por mantener al respecto,

30 En este sentido, NARANJO DE LA CRUZ, op. cit., p. 103 y las obras que allí se citan.

31 PÉREZ REY habla de «la extrema dificultad de vincular, más allá de la retórica, la medida a la creación de empleo o al fomento de la estabilidad» (op. cit., p. 64). Una crítica al vínculo entre facilitación de los despidos y creación de empleo, entre otros, en BAYLOS/PÉREZ REY, op. cit., p. 70; MARTÍNEZ ABASCAL, op. cit., p. 1354; MIÑARRO YANINI, M. (2012). «La flexibilización del despido colectivo por la Ley 3/2012 y su incidencia en la formulación de las causas justificantes: voluntad liberalizadora versus límites jurídicos y función judicial». Relaciones Laborales, núm. 19-20, Sección Doctrina, tomo II, pp. 2-3 (citado por la versión electrónica en pdf, obtenida en laleydigital.es, última visita: 08/01/2013); TOSCANI GIMÉNEZ, D. (2012). «Las reformas llevadas a cabo en el régimen jurídico del despido por la reforma laboral de 2012». Relaciones Laborales, núm. 19-20, Sección Doctrina, tomo II, p. 16. Citado por la versión digital en pdf, que se puede encontrar en laleydigital.es. Última visita: 08/01/2013. Sobre el derecho al 
si no un silencio absoluto, una actitud de autocontención y de reconocimiento al legislador de un considerable margen de decisión. Aun en el caso en que estadísticamente pudiera demostrarse que la creación de esta modalidad contractual ha venido acompañada por una disminución en el volumen de la contratación indefinida, siempre quedaría a disposición de los defensores de la idoneidad de la medida la posibilidad de responder que tal disminución hubiera sido mayor de no haberse realizado el cambio normativo, lo que resulta imposible de comprobar.

Algo parecido sucede con el criterio de necesidad, por la dificultad de aportar de manera incuestionable medidas alternativas capaces de conseguir el incremento —o, según lo expuesto, no disminución — del empleo con la misma intensidad que la legalmente adoptada.

Para realizar, finalmente, el examen de la proporcionalidad en sentido estricto de la medida podemos acudir a los criterios establecidos por la STC 22/1981, que analiza el límite al derecho al trabajo impuesto por razón de una determinada política de empleo, con ocasión del establecimiento por ley de una edad de jubilación forzosa. Aunque son varias las diferencias existentes entre los dos supuestos, en ella se puede apreciar que el TC condiciona la constitucionalidad de la norma entonces sometida a su juicio, por un lado, al aseguramiento de la finalidad perseguida por la política de empleo invocada, y, por otro, a la existencia de una compensación para el titular del derecho al trabajo por el sacrificio personal y económico que experimenta a raíz de la medida (cfr. STC 22/1981, f.j. 10) $)^{32}$. Ninguna de las dos condiciones se da en el caso del contrato indefinido de apoyo a emprendedores. El derecho a la continuidad o estabilidad en el empleo de los trabajadores contratados a través de esta figura queda totalmente a expensas de la voluntad del empresario, sin compensación alguna. Además, al darse entrada en el ordenamiento jurídico a una modalidad contractual con estos rasgos se está favoreciendo la progresiva sustitución de contratos vigentes por otros del tipo analizado, sin que la Ley disponga garantías suficientes para evitar este efecto a medio plazo. De este modo, la consecución del

trabajo como límite de las políticas flexibilizadoras que pretenden lograr el pleno empleo, BAYLOS/PÉREZ REY, op. cit., p. 67. Un resumen de la doctrina alemana sobre el conflicto que esta cuestión encierra entre los trabajadores que ya tienen un puesto de trabajo y los que lo buscan, en PAZ-ARES, C. y ALFARO ÁGUILA REAL, J. (2002). «El derecho a la libertad de empresa y sus límites. La defensa de la productividad de acuerdo con las exigencias de la economía general y de la planificación», en MONEREO PÉREZ, J. L., MOLINA NAVARRETE, C. y MORENO VIDA, M. ${ }^{a}$ N. (dirs.), Comentario a la Constitución Socio-Económica de España, Granada, Comares, p. 434.

32 Acude a la doctrina de esta sentencia para valorar la constitucionalidad de nuestro objeto de estudio, BAZ RODRÍGUEZ, op. cit., pp. 105-106. 
objetivo de creación de empleo «estable» resulta una quimera. Los términos en que la figura contractual aparece legalmente definida permiten un uso abusivo de la misma, contrario a los fines que afirma perseguir ${ }^{33}$. Desarrollaremos a continuación estos argumentos.

En efecto, el trabajador no percibe compensación alguna por la privación que experimenta del derecho a la estabilidad en el empleo durante el primer año de vida del contrato. No se puede considerar compensación a los efectos indicados la previsión contenida en el apartado cuarto del art. 4 de la Ley acerca de que el trabajador pueda voluntariamente compatibilizar cada mes, junto con el salario, el 25 por ciento de la cuantía de la prestación por desempleo de nivel contributivo que tuviera reconocida y que estuviera pendiente de percibir. De esta posibilidad no se benefician todos los trabajadores, puesto que solo se prevé, lógicamente, para quienes en el momento de la contratación estuviera disfrutando de tal prestación. Además, la Ley dispone el cómputo como periodo consumido del 25 por ciento del tiempo en que se compatibilizó la prestación con el trabajo, en el caso de cese en el trabajo que suponga situación legal de desempleo y el beneficiario opte por reanudar la prestación pendiente de percibir (párrafo cuarto del art. 4.4 de la Ley).

Por otra parte, la Ley no garantiza suficientemente la consecución del objetivo proclamado de creación de empleo «estable». Al contrario, los mecanismos introducidos con este fin contienen importantes «fugas», que abren la puerta a una rotación permanente de trabajadores en el puesto en cuestión. Así sucede con el art. 4 de la Ley, que en su apartado 3 dispone que «(n)o podrá establecerse un periodo de prueba cuando el trabajador haya ya desempeñado las mismas funciones con anterioridad en la empresa, bajo cualquier modalidad de contratación» ${ }^{34}$. Este criterio normativo se recoge también en el párrafo tercero del art. $14.1 \mathrm{ET}^{35}$. En este último resulta un criterio útil y proporcionado en relación con el fin de evitar el abuso del periodo de pruebas que se produciría en el caso de someter a prueba en reiteradas ocasiones al mismo trabajador para

33 Como se ha señalado, la norma «ha seguido (...) un criterio sorprendentemente oblicuo y contradictorio, ya que dice pretender favorecer la contratación estable, pero, con un período de prueba tan desbocado y sin explícitas cautelas para impedir la concatenación de los nuevos contratos, está promoviendo la inestabilidad en el empleo» (ESCUDERO RODRÍGUEZ, op. cit., p. 8). Para SÁNCHEZ-URÁN AZAÑA, sin embargo, «resulta contraproducente tachar de irrazonable la medida con fundamento en un prejuicio de abuso o utilización abusiva por el empresario del desistimiento durante el primer año de este contrato» (op. cit., p. 73).

34 Recurre a este artículo para fundamentar su posición favorable a la razonabilidad del plazo, entre otros argumentos, GÓMEZ ABELLEIRA, op. cit., p. 79.

35 «Será nulo el pacto que establezca un período de prueba cuando el trabajador haya ya desempeñado las mismas funciones con anterioridad en la empresa, bajo cualquier modalidad de contratación.» 
el desempeño de idénticas funciones. Sin embargo, la misma limitación resulta absolutamente insuficiente en relación con el objetivo aparentemente perseguido en el contrato de apoyo a emprendedores de creación de empleo estable. Nada en ella impide la cobertura de la función en cuestión por medio de trabajadores contratados de manera sucesiva mediante el encadenamiento de los respectivos contratos de apoyo a emprendedores ${ }^{36}$. Esta rotación indefinida de trabajadores convertiría de facto la modalidad contractual examinada en un contrato temporal sin causa, con la diferencia, además, de que durante ese año el trabajador podría ser libremente despedido en cualquier momento sin coste alguno para la empresa ${ }^{37}$.

También se muestra insuficiente la garantía contenida en el apartado 6 del art. 4 de la Ley, por la que «(n)o podrá concertar el contrato de trabajo por tiempo indefinido de apoyo a los emprendedores a que se refiere el presente artículo, la empresa que, en los seis meses anteriores a la celebración del contrato, hubiera adoptado decisiones extintivas improcedentes. La limitación afectará únicamente a las extinciones producidas con posterioridad a la entrada en vigor de esta Ley, y para la cobertura de aquellos puestos de trabajo del mismo grupo profesional que los afectados por la extinción y para el mismo centro o centros de trabajo» ${ }^{38}$. Lo limitado de su alcance tampoco impide la concatenación de sucesivos contratos de apoyo a emprendedores con distintos trabajadores, en la medida en que las

${ }^{36}$ La doctrina se ha hecho eco de esta posibilidad. Por todos, SÁNCHEZ-URÁN AZAÑA, op. cit., pp. 60-70.

37 Apuntan a este argumento, entre otros, GARCÍA BLASCO, op. cit., p. 15; RAMOS MORAGUES, op. cit., p. 219; TOSCANI GIMÉNEZ, «El fomento...» cit., pp. 22-23; GÓMEZ ABELLEIRA, op. cit., p. 80; MOLINA NAVARRETE, C. (2012). «La versión parlamentaria de la reforma laboral 2012: mayor flexibilidad, mejoras técnicas y "versos sueltos"». Estudios financieros. Revista de trabajo y seguridad social: Comentarios, casos prácticos: recursos humanos, núm. 352, p. 37. Incluso en el «Documento de Trabajo de los Servicios de la Comisión. Evaluación del programa nacional de reforma y del programa de estabilidad de España para 2012, que acompaña al documento Recomendaciones del Consejo relativa al programa nacional de reforma de 2012 de España y por la que se emite un dictamen del Consejo sobre el programa de estabilidad actualizado de España para 2012-2015 \{COM (2012) 310 final\}» apunta al «riesgo de que las empresas utilicen el período de prueba de un año para los nuevos contratos permanentes como forma de convertir este contrato en un contrato temporal de hecho, con costes de rescisión nulos» (p. 34). El documento puede encontrarse en http://ec.europa.eu/europe2020/pdf/nd/swd2012_spain_es.pdf. Aparece citado en MOLINA NAVARRETE, «La versión parlamentaria...», cit., p. 10). Esta comparación con los contratos temporales puede verse en el recurso de los grupos parlamentarios, p. 74.

38 Sobre las insuficiencias de esta norma, RAMOS MORAGUES, op. cit., p. 207. Sobre el significado que debe darse en ella la expresión «decisiones extintivas improcedentes», véase GÓMEZ ABELLEIRA, op. cit., pp. 67-68. 
extinciones producidas durante su primer año de vigencia no son consideradas por la ley como despidos y quedan al margen del control judicial ${ }^{39}$.

Podría oponerse a lo que aquí se sostiene que nuestros argumentos aparecen contrarrestados por las condiciones a las que se ven sometidos los incentivos fiscales y bonificaciones previstos en los apartados cuarto y quinto del art. 4 de la Ley, que persiguen que se realice un uso correcto de la modalidad contractual. En este sentido, dispone su apartado séptimo que «(p)ara la aplicación de los incentivos vinculados al contrato de trabajo por tiempo indefinido de apoyo a los emprendedores, la empresa deberá mantener en el empleo al trabajador contratado al menos tres años desde la fecha de inicio de la relación laboral. Asimismo, deberá mantener el nivel de empleo en la empresa alcanzado con el contrato por tiempo indefinido de apoyo a los emprendedores durante, al menos, un año desde la celebración del contrato. En caso de incumplimiento de estas obligaciones se deberá proceder al reintegro de los incentivos» ${ }^{40}$.

Los estímulos previstos no llegan, sin embargo, a conjurar los riesgos de un uso desviado de la modalidad contractual ${ }^{41}$. De cara al objetivo de lograr la continuidad del trabajador contratado o evitar la amortización posterior de otros puestos de trabajo, su principal debilidad se encuentra en su propia configuración como estímulos en sentido estrictamente positivo, esto es, en el hecho de que la única sanción a la que se arriesga el empresario por no cumplir las condi-

39 GÓMEZ ABELLEIRA, op. cit., p. 68; SÁNCHEZ-URÁN AZAÑA, op. cit., p. 69; MOLINA NAVARRETE, «La versión parlamentaria...», cit., p. 43. La calificación de este encadenamiento de contratos como fraude de ley, propuesta por ESCUDERO RODRÍGUEZ (op. cit., p. 9), privaría paradójicamente a la norma examinada de su sentido ya que esta facultad de libre extinción del contrato constituye el principal medio usado por el legislador para conseguir el fin perseguido, esto es, el fomento del empleo. Menos inconvenientes parece plantear, sin embargo, la aplicación de esta categoría a otras prácticas imaginables de las empresas, como podría ser el juego con la movilidad de personal entre los distintos centros de trabajo, sustituyendo al trabajador despedido improcedentemente con trabajadores de otros centros que, a su vez, fueran reemplazados mediante el contrato de apoyo a emprendedores. $\mathrm{Al}$ respecto, véase ibídem, p. 6.

${ }^{40}$ Una valoración positiva de estos incentivos en SÁNCHEZ-URÁN AZAÑA, op. cit., p. 75; MONTOYA MELGAR, A. (2012). «El contrato de trabajo tras la reforma laboral». Revista Española de Derecho del Trabajo, núm. 155, p. 13, o GÓMEZ ABELLEIRA (op. cit., p. 79), quien, no obstante, considera insuficiente el período de tres años (ibídem, p. 87). En el mismo sentido se manifiesta el Dictamen 5/2012 del Consell de Garanties Estatutàries de Catalunya, de 3 de abril (pp. 81-82). Sobre su insuficiencia, SUÁREZ CORUJO, op. cit., p. 32.

${ }^{41}$ En algún caso puede darse, incluso, el efecto perverso, señalado por la doctrina, de que las cantidades recibidas por la empresa por este concepto excedan de las suficientes para financiar el coste del despido del trabajador contratado, una vez transcurrido el plazo de tres años requerido para consolidar su percepción (GÓMEZ ABELLEIRA, op. cit., p. 72; BAZ RODRÍGUEZ, op. cit., p. 101). 
ciones establecidas consiste en el reintegro de los incentivos ${ }^{42}$. La empresa ni tan siquiera queda impedida para continuar utilizando el contrato de apoyo a emprendedores. En estos términos, el atractivo de una modalidad contractual que permite a la empresa despedir al trabajador libremente durante el primer año de vida del contrato es tal, que el perjuicio consistente en la desactivación de los incentivos puede quedar absolutamente neutralizado ${ }^{43}$.

Por otra parte, los estímulos no alcanzan a todos los supuestos de uso del contrato $^{44}$. La deducción de 3.000 euros de la cuota íntegra del impuesto de sociedades se limita a «(l)as entidades que contraten a su primer trabajador a través de un contrato de trabajo por tiempo indefinido de apoyo a los emprendedores» (art. 43.1 del Real Decreto-Legislativo 4/2004, de 5 de marzo, por el que se aprueba el texto refundido de la Ley del Impuesto sobre Sociedades; la cursiva es nuestra). El resto únicamente opera en el caso en el que el contratado sea un desempleado beneficiario de una prestación contributiva por desempleo, que hubiera percibido esta durante, al menos, tres meses antes del inicio de la relación laboral (caso de la segunda deducción en la cuota íntegra del impuesto de sociedades, prevista en el art. 43.2 del citado Real Decreto-Legislativo); o, en el supuesto de las bonificaciones por tres años en la cuota empresarial a la Seguridad Social, si el trabajador contratado pertenece al colectivo de los jóvenes entre 16 y 30 años o a los mayores de 45 años.

Por encima, sin embargo, de todos estos argumentos, la constitucionalidad de la medida analizada queda cuestionada sobre todo por la importancia que tiene el derecho al no ser despedido sin justa causa como manifestación del derecho al trabajo. Esta vertiente podría llegar a considerarse, sin dificultad, como parte de su contenido esencial ${ }^{45}$.

${ }^{42}$ Cfr. BAZ RODRÍGUEZ, op. cit., p. 106. La insuficiencia de los incentivos para evitar el despido del trabajador, en VIDA SORIA, J., MONEREO PÉREZ, J. L. y MOLINA NAVARRETE, C. (2012). Manual de Derecho del Trabajo, 10. ${ }^{a}$ ed., Granada, Comares, p. 408.

43 En este sentido, ESCUDERO RODRÍGUEZ, op. cit., p. 9. Para PÉREZ REY, «esta suerte de estabilidad potestativa, dependiente de la sola voluntad del empresario durante la primera anualidad, no consigue contrarrestar el apartamiento del art. 35 CE» (op. cit., p. 64).

44 Partimos para esta observación de que nada impide el uso de este contrato para contratar sujetos no incluidos en los colectivos objeto de incentivo (en este sentido, por todos, GÓMEZ ABELLEIRA, op. cit., p. 80, o ESCUDERO RODRÍGUEZ, op. cit., p. 2; en contra, VIDA SORIA/ MONEREO PÉREZ/MOLINA NAVARRETE, op. cit., p. 407.

${ }_{45}$ Así, sostienen la violación de este contenido esencial PÉREZ REY, op. cit., p. 64 o ESCUDERO RODRÍGUEZ, op. cit., p. 9. La causalidad del despido como parte del contenido esencial del derecho al trabajo en, entre otros, BAYLOS/PÉREZ REY, op. cit., p. 140; MARTÍNEZ ABASCAL, op. cit., p. 1336. 
En este sentido, según el alto Tribunal, «(c)onstituyen el contenido esencial de un derecho subjetivo aquellas facultades o posibilidades de actuación necesarias para que el derecho sea recognoscible como pertinente al tipo descrito y sin las cuales deja de pertenecer a ese tipo y tiene que pasar a quedar comprendido en otro desnaturalizándose, por decirlo así» (STC 11/1981, f.j. 8). Un repaso a la evolución histórica del despido en nuestro ordenamiento permite llegar a la conclusión de que el trabajador siempre ha quedado protegido frente al despido libre, sin perjuicio de que, como sostenemos en un epígrafe posterior, el alcance de tal protección deba ser revisada para lograr su total adecuación al texto constitucional. En efecto, la Ley de Contrato de Trabajo de 1944 regulaba como causa de extinción del contrato el «despido justificado del trabajador por el empresario» (art. 76, causa octava) y delimitaba en su art. 77 las que podían ser consideradas justas causas de despido. Esta Ley estuvo vigente hasta la entrada en vigor de la Ley 8/1980, de 10 de marzo, del Estatuto de los Trabajadores, que la derogó en su Disposición Final Tercera. Dos. La norma estatutaria, como es sabido, también ha mantenido siempre la naturaleza causal del despido, en línea con las exigencias derivadas de la doctrina del Tribunal Constitucional. Así pues, es fácil concluir, a partir tanto de la jurisprudencia constitucional como de un repaso histórico de la regulación del despido, que el tipo del derecho al trabajo incluye la protección del trabajador frente al despido sin causa. Esta protección decae durante un año, sin embargo, en el contrato indefinido de apoyo a emprendedores, sin que pueda alegarse, so pena de incurrir en un supuesto de fraude de Constitución, que no estamos en realidad ante un caso de despido, sino de extinción del contrato durante el periodo de prueba.

El carácter coyuntural que otorga a la medida la Disposición Transitoria Novena de la Ley 3/2012 no basta para exceptuar las conclusiones alcanzadas ${ }^{46}$. La gravedad del menoscabo sufrido por el derecho al trabajo no se ve reducida por una limitación temporal cuyo fin, por otra parte, a la vista de la alarmante situación de desempleo existente en nuestro país, podría demorarse bastante tiempo.

En definitiva, a nuestro juicio, el mal llamado «período de prueba de un año» previsto en la Ley 3/2012 encubre en realidad, en fraude de Constitución, la concesión al empresario de una facultad de despido libre del trabajador contra-

${ }^{46}$ Entre otros, SUÁREZ CORUJO, op. cit., p. 32; MOLINA NAVARRETE, op. cit., p. 37; BAZ RODRÍGUEZ, op. cit., p. 107; VIDA SORIA/MONEREO PÉREZ/MOLINA NAVARRETE, op. cit., p. 409. En otro sentido, GARCÍA BLASCO, op.cit, pp. 16-17. Según la Disposición transitoria novena. 2 de la Ley, «(h)asta que la tasa de desempleo en nuestro país se sitúe por debajo del 15 por ciento podrán realizarse contratos de trabajo por tiempo indefinido de apoyo a los emprendedores a que se refiere el artículo 4 de esta Ley». 
tado durante un período de un año, lo que vulnera el derecho a no ser despedido sin justa causa que forma parte del derecho al trabajo del art. $35.1 \mathrm{CE}^{47}$.

\section{ESTÍMULO A LA CONTRATACIÓN DE PERCEPTORES DE LA PRESTACIÓN CONTRIBUTIVA POR DESEMPLEO E IGUALDAD EN EL ACCESO A UN PUESTO DE TRABAJO}

El régimen jurídico del contrato por tiempo indefinido de apoyo a emprendedores presenta otro elemento cuestionable desde el punto de vista de su constitucionalidad, esta vez referido a los estímulos creados para su uso por las empresas. Nos estamos refiriendo concretamente a la posible discriminación en la que incurriría el art. 43.2 de la Ley del Impuesto de Sociedades, tras su modificación por la Disposición Final Decimoséptima de la Ley 3/2012, al prever una deducción en su cuota íntegra a favor de la empresa que contrate bajo esta modalidad a un desempleado beneficiario de una prestación contributiva por desempleo, que hubiera percibido esta prestación durante al menos tres meses antes del inicio de la relación laboral ${ }^{48}$.

${ }^{47}$ Sostienen la inconstitucionalidad de la figura, BAYLOS GRAU, op. cit., p. 13; SUÁREZ CORUJO, op. cit., p. 32; BAZ RODRÍGUEZ, op. cit., pp. 103 y ss.; MOLINA NAVARRETE, «Intermediación...», cit., p. 156; PÉREZ REY, op. cit., pp. 63-64; TOSCANI GIMÉNEZ, «El fomento...», cit., p. 23; MORENO VIDA, op. cit., pp. 199-200; VALDÉS ALONSO, A. (2012). «La extinción del contrato de trabajo por tiempo indefinido de apoyo a los emprendedores y el despido objetivo», en LAHERA FORTEZA, J. (coord.), Reforma Laboral 2012: preguntas y respuestas, Madrid, Ediciones Cinca, pp. 55 y 77. Entienden justificada la duración del período de prueba, GÓMEZ ABELLEIRA, op. cit., pp. 79 y 91; SÁNCHEZ-URÁN AZAÑA, op. cit., pp. 73-75 y GARCÍA BLASCO, op. cit., pp. 16-17.

48 Según el precepto citado, «(s)in perjuicio de lo dispuesto en el apartado anterior, las entidades que tengan una plantilla inferior a 50 trabajadores en el momento en que concierten contratos de trabajo por tiempo indefinido de apoyo a los emprendedores, definido en el artículo 4 de la Ley de Medidas Urgentes para la Reforma del Mercado Laboral, con desempleados beneficiarios de una prestación contributiva por desempleo regulada en el Título III del Texto Refundido de la Ley General de la Seguridad Social, aprobado por el Real Decreto Legislativo 1/1994, de 20 de junio, podrán deducir de la cuota íntegra el 50 por ciento del menor de los siguientes importes:

a) El importe de la prestación por desempleo que el trabajador tuviera pendiente de percibir en el momento de la contratación.

b) El importe correspondiente a doce mensualidades de la prestación por desempleo que tuviera reconocida.

Esta deducción resultará de aplicación respecto de aquellos contratos realizados en el periodo impositivo hasta alcanzar una plantilla de 50 trabajadores, y siempre que, en los doce meses siguientes al inicio de la relación laboral, se produzca, respecto de cada trabajador, un incremento 
En virtud de este precepto, la Ley estimula la contratación del desempleado que cobre la prestación contributiva por desempleo. Este se encuentra, pues, en mejor situación de cara a su contratación por cualquier empresa que un desempleado que no cobre tal prestación, en la medida en que ella se beneficia en tal caso de las correspondientes deducciones en la cuota íntegra del impuesto de sociedades. Cabe preguntarse, pues, si de este modo el trabajador que no cobra el desempleo es objeto de discriminación en relación con su «igual derecho (...) a un determinado puesto de trabajo si se cumplen los requisitos necesarios de capacitación» (STC 22/1981, f.j. 8), inserto en el art. 35.1 CE e íntimamente conectado con el derecho a la igualdad del art. $14 \mathrm{CE}$.

Como señala el TC en su sentencia 200/2001, «(e)l juicio de igualdad es de carácter relacional. Requiere como presupuestos obligados, de un lado, que, como consecuencia de la medida normativa cuestionada, se haya introducido directa o indirectamente una diferencia de trato entre grupos o categorías de personas (STC 181/2000, de 29 de junio, FJ 10) y, de otro, que las situaciones subjetivas que quieran traerse a la comparación sean, efectivamente, homogéneas o equiparables, es decir, que el término de comparación no resulte arbitrario o caprichoso (SSTC 148/1986, de 25 de noviembre, FJ 6; 29/1987, de 6 de marzo, FJ 5; 1/2001, de 15 de enero, FJ 3). Sólo una vez verificado uno y otro presupuesto resulta procedente entrar a determinar la licitud constitucional o no de la diferencia contenida en la norma» (f.j. 5).

La STC $125 / 2003$, por su parte, señala que el principio de igualdad prohíbe al legislador «configurar los supuestos de hecho de la norma de modo tal que se dé trato distinto a personas que, desde todos los puntos de vista legítimamente adoptables, se encuentran en la misma posición o, dicho de otro modo, impidiendo que se otorgue relevancia jurídica a circunstancias que, o bien no pueden ser jamás tomadas en consideración por prohibirlo así expresamente la propia Constitución, o bien no guardan relación alguna con el sentido de la regulación que, al incluirlas, incurre en arbitrariedad y es por eso discriminatoria» (SSTC 144/1988, f.j. 1; 125/2003, f.j. 4; 84/2008, f.j. 6).

Las situaciones subjetivas que aquí se analizan cumplen el requisito de homogeneidad exigible. En ambos casos estamos ante personas desempleadas con el

de la plantilla media total de la entidad en, al menos, una unidad respecto a la existente en los doce meses anteriores.

La aplicación de esta deducción estará condicionada a que el trabajador contratado hubiera percibido la prestación por desempleo durante, al menos, tres meses antes del inicio de la relación laboral. A estos efectos, el trabajador proporcionará a la entidad un certificado del Servicio Público de Empleo Estatal sobre el importe de la prestación pendiente de percibir en la fecha prevista de inicio de la relación laboral. 
mismo derecho a acceder a un puesto de trabajo si reúnen las condiciones de capacitación requeridas. El término de comparación no es, pues, arbitrario o caprichoso. Considerar el cobro de la prestación por desempleo como un factor justificado de diferenciación entre ellos no sería sino un fácil expediente para eludir, de entrada, un examen en profundidad de la cuestión, que no es otra, precisamente, que la determinación de si ese puede ser un elemento de distinción entre trabajadores a los efectos de la adopción de políticas de estímulo a la contratación ${ }^{49}$.

Para el TC, el principio de igualdad «veda la utilización de elementos de diferenciación que quepa calificar de arbitrarios o carentes de una justificación razonable. Lo que prohíbe el principio de igualdad son, en suma, las desigualdades que resulten artificiosas o injustificadas por no venir fundadas en criterios objetivos y razonables, según criterios de valor generalmente aceptados» (STC 39/2002, f.j. 4). Para saber, sin embargo, si el elemento de diferenciación consistente en el cobro de la prestación por desempleo es arbitrario o carente de justificación es necesario ver, en primer lugar, si el trato desigual persigue un fin, y, en su caso, cuál es este. En el supuesto que nos ocupa, el fin perseguido es obvio: la reducción de los gastos del Estado en el capítulo de prestaciones por desempleo, en una época, además, en la que se unen una tasa extraordinariamente alta de paro con un elevado déficit público. Este objetivo encuentra una clara cobertura constitucional en el principio de estabilidad presupuestaria del art. 135.1 CE, por lo que es apto, en principio, para ser utilizado como fundamento de un trato desigual entre supuestos de hecho homogéneos.

Sucede, sin embargo, que no basta con que el trato desigual esté justificado en estos términos para que sea conforme con el art. 14 CE. Como señala el TC, «(t)ambién es necesario, para que sea constitucionalmente lícita la diferencia de trato, que las consecuencias jurídicas que se deriven de tal distinción sean proporcionadas a la finalidad perseguida, de suerte que se eviten resultados excesivamente gravosos o desmedidos. En resumen, el principio de igualdad, no sólo exige que la diferencia de trato resulte objetivamente justificada, sino también que supere un juicio de proporcionalidad en sede constitucional sobre la relación

49 Sin embargo, como se ha afirmado, «(e)l margen de discrecionalidad que permite el término de comparación, puede hacer incurrir al Tribunal en razonamientos perfectamente discrecionales. En cierta medida porque la valoración del término de comparación constituye una válvula de escape al rigor de la justicia constitucional (STC 184/2007, de 10 de septiembre). La consideración de que exista o no un término de comparación adecuado, se basa a veces en razonamientos perfectamente discutibles» [BALAGUER CALLEJÓN, M. ${ }^{a}$ L. (2010). Igualdad y Constitución Española, Madrid, Tecnos, pp. 90-91]. Para un estudio detenido del término de comparación puede verse GAVARA DE CARA, J. C. (2005). Contenido y función del término de comparación en la aplicación del principio de igualdad, Cizur Menor (Navarra), Thomson/Aranzadi. 
existente entre la medida adoptada, el resultado producido y la finalidad pretendida» [STC 200/2001, f.j. 4.a)]. Es esta la exigencia que entendemos incumplida con el establecimiento de tales deducciones.

El incentivo analizado sitúa en peor condición, de cara a su contratación por una empresa, al trabajador en paro que no está recibiendo una prestación por desempleo frente al que sí lo hace. El efecto que ello produce es absolutamente contrario a las exigencias básicas de un Estado social, en el que se procura la defensa del que ocupa una posición socialmente débil en aras de una igualdad real (art. 9.2 CE). El desempleo es considerado por la Constitución como una situación de especial necesidad en su art. $41 \mathrm{CE}$, para lo que se dispone que se garanticen la asistencia y prestaciones sociales suficientes, sin las cuales el individuo afectado se encuentra con grandes dificultades para satisfacer sus necesidades vitales básicas y las de su familia (art. 39.1 CE). Pues bien, el efecto de la deducción creada es precisamente el contrario al que la lógica del Estado social impone, que sería atender a esta situación fomentando la contratación de los parados de larga duración que no perciben prestaciones contributivas por desempleo. La norma analizada promueve, por el contrario, una perpetuación de su situación, que dejaría al colectivo afectado en un claro riesgo de exclusión social; todo ello en clara contradicción con la vertiente arriba citada del art. $35.1 \mathrm{CE}^{50}$.

A diferencia de lo que ocurre con otros incentivos a la contratación laboral, que pretenden situar a determinados colectivos que se encuentran en una situación desfavorecida en una posición de igualdad sustancial en este ámbito de la realidad social (art. 9.2 CE), el que aquí examinamos castiga al colectivo que se halla en tal posición de debilidad en aras de la consecución de un objetivo, el equilibrio presupuestario, que no guarda relación alguna con el ámbito laboral en el que se introduce el trato desigual.

En definitiva, el fomento de la contratación de trabajadores que cobran la prestación contributiva por desempleo en los términos de la Ley 3/2012, en perjuicio del resto, constituye un trato discriminatorio en la medida en que les otorga un trato desigual con efectos absolutamente desproporcionados en relación con el fin que persigue ${ }^{51}$.

${ }^{50}$ Críticos también con la medida por los motivos indicados, TOSCANI GIMÉNEZ, «El fomento...», cit., p. 17; BAZ RODRÍGUEZ, op. cit., p. 111; ESCUDERO RODRÍGUEZ, op. cit., pp. 2 y 13. Para GÓMEZ ABELLEIRA, sin embargo, «se trata, sin duda, de una finalidad legítima, por mucho que incentivar la contratación del perceptor de desempleo pueda causar un perjuicio en abstracto al colectivo de desempleados que ya no reciben, o que nunca han recibido, la prestación contributiva» (op. cit., p. 86).

${ }^{51}$ En este sentido, CASAS BAAMONDE, M. ${ }^{a}$ E., RODRÍGUEZ-PIÑERO Y BRAVOFERRER, M. y VALDÉS DAL-RÉ, F. (2012). «La nueva reforma laboral». Relaciones Laborales, 


\section{ESTUDIO CRÍTICO DEL RÉGIMEN LEGAL DEL DESPIDO IMPROCEDENTE Y LOS SALARIOS DE TRAMITACIÓN DESDE UNA PERSPECTIVA CONSTITUCIONAL}

\subsection{Planteamiento inicial}

Dedicaremos este apartado al estudio de la constitucionalidad de la supresión de los salarios de tramitación en el supuesto de despido improcedente en el que el empresario opta por la indemnización ${ }^{52}$. En la configuración que del despido improcedente realiza el Estatuto de los Trabajadores, la declaración de improcedencia determina la concesión al empresario de un derecho a elegir entre la readmisión del trabajador despedido o el abono a este de una indemnización. Así, a partir de la Ley 3/2012, mientras que la readmisión implica el pago de los salarios de tramitación correspondientes, no ocurre lo mismo cuanto se opta por la indemnización. En tal caso, el contrato se considera extinguido, no desde la fecha de la sentencia o, en su caso, del ejercicio por el empresario de su derecho de opción, sino desde el momento en que se produjo el despido mismo.

El recurso de inconstitucionalidad presentado por los grupos parlamentarios sostiene que la supresión de los salarios de tramitación en los supuestos de despido improcedente en los que el empresario opta por la indemnización implica una lesión del derecho a la estabilidad en el empleo, contenido en el derecho al trabajo (art. 35.1 CE) y del derecho a la igualdad (art. $14 \mathrm{CE})^{53}$. La vulneración

núm. 5, Sección Editorial, tomo 1, pp. 15-16. Citado por versión electrónica en pdf, en laleydigital.es. Última visita 08/01/2013).

$52 \mathrm{El}$ art. 18 de la Ley, en su apartado Ocho, da una nueva redacción al artículo 56.2 ET, en virtud de la cual: «(e)n caso de que se opte por la readmisión, el trabajador tendrá derecho a los salarios de tramitación. Estos equivaldrán a una cantidad igual a la suma de los salarios dejados de percibir desde la fecha de despido hasta la notificación de la sentencia que declarase la improcedencia o hasta que hubiera encontrado otro empleo, si tal colocación fuera anterior a dicha sentencia y se probase por el empresario lo percibido, para su descuento de los salarios de tramitación». La mejor comprensión de este precepto exige su lectura conjunta con el apartado 1 del citado art. 56, que establece que «(c)uando el despido sea declarado improcedente, el empresario, en el plazo de cinco días desde la notificación de la sentencia, podrá optar entre la readmisión del trabajador o el abono de una indemnización equivalente a treinta y tres días de salario por año de servicio, prorrateándose por meses los períodos de tiempo inferiores a un año, hasta un máximo de veinticinco mensualidades. La opción por la indemnización determinará la extinción del contrato de trabajo, que se entenderá producida en la fecha del cese efectivo en el trabajo».

53 Fundamento jurídico 8. Apunta a la posible inconstitucionalidad de la reforma en este punto, por discriminatoria, CRUZ VILLALÓN, «Los cambios...», cit., p. 17. Considera constitucional la desaparición de los salarios de tramitación, en tanto que opción de política legislativa, SAGARDOY BENGOECHEA, «Los derechos constitucionales...», cit., p. 375. Una valoración 
del primero de los derechos mencionados tiene lugar al favorecer la norma legal la solución menos respetuosa con la estabilidad en el empleo, esto es, la extinción de la relación laboral con la correspondiente indemnización, en la medida en que el empresario queda liberado en tal caso del abono de los salarios de tramitación. Por lo que respecta al derecho a la igualdad, se invoca una doble discriminación: del empresario que readmite, que se ve obligado al abono de los salarios de tramitación, respecto del que opta por la indemnización, y del trabajador improcedentemente despedido que ha sido indemnizado por ello en relación con el que ha sido readmitido ${ }^{54}$.

La existencia de una posible discriminación del trabajador indemnizado frente al readmitido ha sido ya rechazada por el TC en sede de recurso de amparo, en la STC 84/2008 55 . En su fundamento jurídico 7, el TC, aun reconociendo que los supuestos de hecho examinados parten de idéntica situación de origen, sostiene que la situación se desdobla a partir del ejercicio por el empresario de su derecho de opción, dando lugar a su juicio a dos supuestos plenamente diferenciados: «en uno, el trabajador es readmitido en la empresa, quedando sin efecto el despido; en el otro, el contrato del trabajador queda definitivamente extinguido. $\mathrm{Y}$ es respecto de dicha situación donde opera la diferencia de trato establecida por el legislador, al reconocer exclusivamente al primero y no al segundo el derecho al cobro de «los salarios dejados de percibir» desde la fecha del despido hasta la de notificación de la Sentencia». Así, entiende el TC, «las situaciones traídas a comparación no son, en modo alguno, homogéneas, sino, antes al contrario, radicalmente diferentes».

El alto Tribunal sostuvo entonces que «la diferenciación introducida por el legislador no resulta desproporcionada o irrazonable, en la medida en que se corresponde, a partir de una determinada configuración legal del despido, con el contenido del derecho de opción reconocido al empresario y con los efectos sobre la vigencia del contrato de trabajo derivados del ejercicio de dicho derecho» (la cursiva es nuestra).

positiva de la reforma puede verse en LAHERA FORTEZA, J. (2012). «Medidas en contratación laboral y despido en la Ley 3/2012». Relaciones Laborales, núm. 15-18, p. 6. Citada por la versión digital en pdf, en laleydigital.es; última visita el 08/01/2012).

54 Véase p. 82 del recurso.

55 Su doctrina se repite posteriormente en las SSTC 122 y 143/2008. Más recientemente, el ATC de 12 de febrero de 2014 reproduce esta jurisprudencia anterior (f.j. 6. A.a). Téngase en cuenta que la supresión de los salarios de tramitación en los supuestos de indemnización realizada por la Ley 3/2012 tuvo un antecedente en el art. 2.3 del Real Decreto-ley 5/2002, de 24 de mayo, de medidas urgentes para la reforma del sistema de protección por desempleo y mejora de la ocupabilidad, que fue posteriormente derogada por la Ley 45/2002, de 12 de diciembre. Este Real Decreto-ley fue declarado inconstitucional por la STC 68/2007, de 28 de marzo, por vulneración del art. 86.1 CE. 
El planteamiento del TC merece una revisión crítica desde dos puntos de vista. Por un lado, es necesario poner de manifiesto la falta de sintonía de la propia configuración legal del despido improcedente con el significado constitucional del derecho al trabajo. Podremos ver entonces que tal configuración, de la que hace depender el TC el sentido de su pronunciamiento, es, en sí misma, contraria a la Constitución. Esto despejará el camino para, finalmente, poder concluir que la supresión de los salarios de tramitación en los términos de la Ley $3 / 2012$ entraña un trato discriminatorio contrario al art. 14 CE.

\subsection{El despido improcedente: un análisis constitucional}

Si nos salimos de la lógica interna del régimen legal del despido improcedente, planteamiento seguido por el TC, y examinamos por el contrario su propia conformidad con la Constitución, podríamos llegar a la conclusión de que la norma en cuestión casa mal con las exigencias derivadas del derecho al trabajo en varios aspectos ${ }^{56}$.

En este sentido, interesa destacar en primer lugar que la extinción de la relación laboral calificada como despido improcedente, en la medida en que constituye un despido sin causa, es lesivo por su propia naturaleza del derecho constitucional del art. 35.1 CE. Un despido sin causa es, por tanto, un despido contrario a la Constitución. Es lícito plantearse, en tal caso, cuál debe ser la consecuencia de dicha contradicción. La más elemental lógica jurídica parece indicar que esta no puede ser sino la nulidad del acto inconstitucional, con la consiguiente readmisión del trabajador inconstitucionalmente despedido ${ }^{57}$.

56 Así, entre otros, SASTRE IBARRECHE, op. cit., p. 255.

57 En este sentido, entre otros, GARCÍA LÓPEZ, R. (1984). «Consideraciones en torno a la figura del despido». Revista de Política Social, núm. 143, p. 76; MONTOYA MELGAR, A. (1987). «La extinción del contrato de trabajo», en DURÁN LÓPEZ, F., MONTOYA MELGAR, A. y SALA FRANCO, T., El ordenamiento español y los limites a la autonomía de las partes y a las facultades del empresario, Madrid, Ministerio de Trabajo y Seguridad Social, pp. 265-266; MARTÍNEZ ABASCAL, op. cit., p. 1339; MONEREO PÉREZ, J. L. y MOLINA NAVARRETE, C. (2002). «El derecho al trabajo, la libertad de elección de profesión u oficio: principios institucionales del mercado de trabajo», en MONEREO PÉREZ/MOLINA NAVARRETE/MORENO VIDA (dirs.), op. cit., p. 334; GÁRATE CASTRO, F. J. (2007). «La reforma del régimen jurídico del despido; en particular de los salarios de tramitación», en AA. VV., Calificación y consecuencias del despido improcedente y por causas objetivas, Cizur Menor (Navarra), Thomson Aranzadi, p. 132. Véase también al respecto BAYLOS/PÉREZ REY, op. cit., p. 63. Estos autores proponen, sin embargo, limitar el efecto de nulidad a los despidos sin causa, manteniendo la improcedencia para aquellos donde existe «una, aunque sea mínima, aportación probatoria empresarial de las causas que justifican la extinción y a pesar de que las mismas no se consideren suficientes para legitimar el despido» 
Sin embargo, el Estatuto de los Trabajadores limita el efecto de nulidad, por lo que aquí interesa, al «despido que tenga por móvil alguna de las causas de discriminación prohibidas en la Constitución o en la Ley, o bien se produzca con violación de derechos fundamentales y libertades públicas del trabajador» (art. $55.5 \mathrm{ET})^{58}$. Gracias a una interpretación literal del precepto, los derechos constitucionales cuya violación conduce a la nulidad del despido son solo, junto con el derecho a la igualdad del art. 14 CE, los incluidos en la Sección primera del Capítulo II del Título primero (arts. 15 a 29 CE), que son los únicos así denominados expresamente en el texto constitucional.

La Constitución no ofrece, sin embargo, argumento alguno para reducir la calificación de despido nulo con deber de readmisión a tales supuestos ${ }^{59}$. La especificidad de los derechos de la Sección primera se concreta únicamente en la posibilidad de cualquier ciudadano de recabar su tutela «ante los Tribunales ordinarios por un procedimiento basado en los principios de preferencia y sumariedad y, en su caso, a través del recurso de amparo ante el Tribunal Constitucional» (art. 53.2 CE). La razón de la nulidad de los despidos contrarios a estos derechos no se debe buscar, por tanto, en una inexistente especial protección que, a estos efectos, les otorgue el texto constitucional, sino en su propia normatividad constitucional, rasgo plenamente compartido por el derecho al trabajo del art. 35.1 $\mathrm{CE}^{60}$. La limitación apreciable en la jurisprudencia constitucional de la declaración de nulidad a los despidos contrarios al derecho a la igualdad o a los derechos comprendidos entre los arts. 15 y 29 CE se explica fácilmente si tene-

(ibídem, pp. 122-123). En contra de lo que aquí se sostiene, SAGARDOY BENGOECHEA, op. cit., pp. 374-375 o GOERLICH PESET, J. M. (2005). «Libertad de empresa y extinción del contrato de trabajo», en PÉREZ DE LOS COBOS ORIHUEL (dir.), op. cit., p. 235.

58 Otros supuestos de despidos nulos se encuentran recogidos en los apartados a), b) y c) del art. 55.5 ET.

59 BAYLOS/PÉREZ REY, op. cit., pp. 64 y 122; MONEREO PÉREZ/MOLINA NAVARRETE, op. cit., p. 333. El ATC de 12 de febrero de 2014 se limita a afirmar que «la ilícita decisión extintiva del empresario conlleva un daño cualificado por haberse producido con discriminación o violación de los derechos fundamentales y libertades públicas» [f.j. 5. A.b)].

${ }^{60}$ Como se ha señalado en relación con los derechos de la Sección Segunda del Capítulo II del Título I, entre los que se encuentra el derecho al trabajo, «las carencias en materia de garantías no perjudica su posición normativa en el plano jurídico-constitucional, aunque es obvio que sí perjudica su práctica social, lo que es determinante para su análisis sociológico — no irrelevante para el jurídico — pero no para su análisis dogmático — básico para el jurídico— « [MOLINA NAVARRETE, C. (2003). ««Protección» y «eficacia» de los derechos socio-laborales: balance y perspectivas del sistema constitucional de garantías», en SEMPERE NAVARRO (dir.), El modelo... cit., p. 1178]. 
mos en cuenta que son estos despidos los únicos susceptibles de ser revisados por el TC en amparo ${ }^{61}$.

El reconocimiento legal de la indemnización como alternativa viable a la readmisión en los casos de despido improcedente, por su parte, neutraliza en la práctica la exigencia constitucional de justa causa de despido, al otorgar cobertura normativa a los despidos en los que esta no se satisface. Los despidos sin causa son finalmente admitidos en el ordenamiento, en abierta contradicción con el art. 35.1 CE, con tal que el empresario abone al trabajador la cantidad estipulada en concepto de indemnización ${ }^{62}$. La función normativa de la justa causa sufre así injustificadamente una mutación, al pasarse de ser considerada su concurrencia condición sine qua non de la licitud constitucional del despido, a suponer su ausencia una mera condición de la imposición al empresario de un deber indemnizar al trabajador despedido ${ }^{63}$.

Por otro lado, como el propio TC reconoce en la sentencia arriba citada, «el elemento determinante de la regulación analizada lo constituye la consideración de que el contrato de trabajo ha quedado plenamente extinguido en la fecha del despido, salvo que el empresario opte posteriormente por la readmisión, de manera que la impugnación del despido permitirá determinar su procedencia o improcedencia (o, en su caso, su nulidad), con las consecuencias que de ello hayan de derivarse tras el ejercicio del derecho empresarial de opción, ya sea la indemnización o la readmisión, pero sin alterar en el primer caso la fecha de efectos del despido» (STC 84/2008, f.j. 7).

${ }^{61} \mathrm{La}$ jurisprudencia constitucional sobre la nulidad de los despidos contrarios a derechos fundamentales puede verse, entre otras muchas, en las SSTC 38/1981, f.j. 7; 88/1985, f.j. 4; 66/1993, f.j. 2; 140/1999, f.j. 3.

${ }^{62}$ Sobre la insuficiencia de la indemnización como reacción al despido sin causa, véanse, entre otros, MARTÍNEZ ABASCAL, op. cit., p. 1340; BAYLOS/PÉREZ REY, op. cit., pp. 60 y 63; BLASCO PELLICER, «La extinción...», cit., p. 455. Para MONTOYA MELGAR, la construcción legal «supone, evidentemente, una desviación del principio de despido causal del que parte; principio que queda conculcado en la propia ley, que, de hecho, consagra, sólo que con técnica contradictoria, la figura del despido sin causa (indemnizado)» («La extinción...», cit., p. 266). Defiende la constitucionalidad de la monetización del despido, con argumentos a nuestro juicio insuficientes, y sitúa el problema en la necesidad de que la indemnización sea acorde con los daños y perjuicios realmente sufridos por el trabajador, GORELLI HERNÁNDEZ, J. (2010). El coste económico del despido o el precio de la arbitrariedad. Un estudio sobre la eficacia del despido disciplinario ilícito, Consejo Andaluz de Relaciones Laborales, pp. 20-21, 24, 52-53.

${ }^{63}$ Cfr. al respecto GARCÍA LÓPEZ, op. cit., p. 66; GORELLI HERNÁNDEZ, El coste económico..., cit., p. 27. Por lo demás, la concurrencia de justa causa no siempre exime del deber del empresario de abonar una indemnización al trabajador despedido, como se pone de manifiesto en los despidos colectivos o por causas objetivas (cfr. GARCÍA LÓPEZ, op. cit., p. 66). 
Este elemento, sin embargo, entraña una abierta contradicción con la normatividad de la Constitución, pues no se puede entender qué sentido tiene reconocer la eficacia del acto de un empresario que ha sido lesivo de un derecho constitucional ${ }^{64}$. Al otorgarse pleno efecto extintivo a la decisión extintiva sin causa del empresario se está ignorando el carácter normativo del derecho al trabajo sin una justificación constitucional, puesto que la libertad de empresa no llega a amparar este resultado.

Por último, tampoco se explica, desde una perspectiva constitucional, la concesión que realiza la norma estatutaria de la facultad de optar por una de las consecuencias legalmente previstas precisamente al empresario que, recordémoslo una vez más, ha lesionado un derecho constitucional con su acto ilícito ${ }^{65}$. La ponderación constitucional de la libertad de empresa con el derecho al trabajo arroja como punto de equilibrio entre ambos la preeminencia de la primera únicamente cuando existen causas justificadas del despido del trabajador, luego en defecto de estas ha de prevalecer la posición jurídica del trabajador. Determinada la ilicitud del ejercicio por el empresario de su facultad extintiva, este se sitúa fuera del orden constitucional, con lo que el derecho del art. 38 CE no alcanza a cubrir, por tanto, la concesión a aquél del derecho de opción ${ }^{66}$.

${ }^{64}$ Cfr. MONEREO PÉREZ/MOLINA NAVARRETE, op. cit., p. 334; GÁRATE CASTRO, «La reforma...», cit., p. 143. Como señala GARCÍA LÓPEZ, «si la simple manifestación de voluntad del empresario, con independencia de la causa, de dar por terminada la relación laboral que le vinculaba con el trabajador es respetada íntegramente por el ordenamiento reconociéndole plenos efectos extintivos, no cabe duda de que tan despido sería el procedente (con causa) como el improcedente (sin causa), y que el despido en nuestro Derecho adquiriría los caracteres de un auténtico despido ad nutum, entendiendo por tal a la extinción del contrato por voluntad del empresario que no requiere el apoyo en causa jurídica alguna» (op. cit., p. 65). Crítica también con esta solución, pero desde la óptica de la lógica contractual FERNÁNDEZ LÓPEZ, M. ${ }^{a}$ F. (2012). «La reforma del régimen del despido por la vía de la reducción de sus costes». Revista de Derecho Social, núm. 57, p. 206.

${ }^{65}$ En esta contradicción incurre el ATC de 12 de febrero de 2014, que si bien reconoce «la culpabilidad del empresario en la extinción» y otorga a este factor la condición de elemento de graduación de la indemnización (mayor en el despido improcedente y menor en el colectivo u objetivo), considera que la concesión al empresario del derecho de opción entra dentro del ámbito de configuración del legislador [f.j. 5. A.b)]. Partidarios de que la opción corresponda al trabajador, entre otros, MONTOYA MELGAR, «La extinción...», cit., p. 266; SASTRE IBARRECHE, op. cit., p. 251; MONEREO PÉREZ/MOLINA NAVARRETE, op. cit., p. 335.

${ }_{66}$ En este sentido, se ha indicado que «(n)o existe ninguna razón de fondo para que ante un mismo hecho ilícito (un despido improcedente) sea la simple opción del empresario la que determine el derecho o no del trabajador a los salarios dejados de percibir» [ALBIOL MONTESINOS, I. y BLASCO PELLICER, A. (2002). Desempleo y despido en la reforma laboral del Real Decreto-ley 5/2002, Valencia, Tirant lo Blanch, p. 77]. Para GOERLICH PESET, «el reconocimiento legislativo de una facultad empresarial de opción entre reconstitución del contrato o consolidación 
En definitiva, la configuración legal del despido realizada por el legislador es contraria al art. 35.1 CE y arbitraria, en el significado que a este término otorga el TC: «al enjuiciar un precepto legal al que se tacha de arbitrario, nuestro examen ha de centrarse en determinar si dicho precepto establece una discriminación, pues la discriminación entraña siempre una arbitrariedad, o bien si, aun no estableciéndola, carece de toda explicación racional, lo que también evidentemente supondría una arbitrariedad» (STC 60/2010, f.j. 13, entre otras muchas).

\subsection{Constitución y supresión de los salarios de tramitación}

En el apartado anterior hemos podido comprobar cómo el legislador ha realizado una configuración legal del despido improcedente contraria a las exigencias que se derivan de la propia jurisprudencia constitucional existente sobre el derecho al trabajo. Como hemos visto, la STC 84/2008 parte de dicha configuración en el examen realizado para determinar la posible existencia de discriminación en la supresión de los salarios de tramitación para los trabajadores improcedentemente despedidos cuando el empresario opta por la indemnización. Por tanto, el carácter viciado del punto de partida adoptado por el TC no puede sino contaminar el resultado al que llega el alto Tribunal en esta cuestión.

El sentido constitucional del abono de los salarios de tramitación, a la luz de la normatividad del derecho al trabajo, no se encuentra, como sugiere el TC, en que tras la readmisión «debe entenderse que (el trabajador) ha mantenido en todo momento en vigor su relación laboral con la empresa, pese a no haber prestado servicios efectivos por causa a él no imputable» (STC 84/2008, f.j. 7). Esta afirmación solo puede ser realizada nuevamente desde la propia lógica interna de la construcción legal. De otro modo, no se podría entender el motivo por el que

\footnotetext{
definitiva del despido con pago de una indemnización resulta, según creo, absolutamente ajeno a la libre empresa: llegado este punto estamos en el terreno de la delimitación por el legislador de los efectos derivados de un acto ilegítimo y, difícilmente por tanto, puede traerse a colación aquella libertad para considerar que una determinada opción de política legislativa debe prevalecer sobre otras, más o menos favorables a los intereses empresariales» («Libertad de empresa...», cit., pp. 240-241) No estamos, por tanto, de acuerdo con la posición de los recurrentes cuando rechazan que «no quepan en el marco constitucional soluciones legales alternativas a la readmisión en los casos de despido improcedente; ni que el cese definitivo de la relación contractual con el abono de una indemnización como medida compensatoria choque con el artículo 35.1 de la Constitución; ni, en fin, tampoco hay que olvidar que precisamente es el empresario quien, con carácter general, está facultado para elegir entre las dos opciones. Todo ello encuentra amparo en la libertad de empresa reconocida en el artículo 38 de la Constitución y que sirve para modular la aplicación del derecho al trabajo y sus implicaciones» (pp. 86-87).
} 
históricamente se ha reconocido de manera ininterrumpida el derecho de todo trabajador injustamente despedido a cobrarlos ${ }^{67}$.

Los salarios de tramitación hallan su significado constitucional, más bien, en la mera constatación de que la relación laboral nunca debió haber sido ilícitamente extinguida a iniciativa del empresario, con vulneración del derecho a la continuidad en el empleo del art. $35.1 \mathrm{CE}^{68}$. Desde este punto de vista, la posición de cualquier trabajador improcedentemente despedido es sustancialmente idéntica, ya que en todo caso este es víctima de la lesión de un derecho constitucional del que es titular. Ha sido, por tanto, el propio legislador el que, al configurar normativamente el régimen jurídico del despido improcedente, ha creado artificialmente las bases para distinguir entre dos supuestos de hecho que son, repetimos, sustancialmente idénticos ${ }^{69}$. Utilizar, para negar el carácter discriminatorio de la norma estatutaria, la cobertura que concede la construcción por ella misma creada supone confundir el examen propio del art. $14 \mathrm{CE}$, que tiene como objeto los supuestos de hechos comparados, con otro distinto, cuyo objeto es la lógica interna de la norma cuestionada.

Los argumentos que ofrece el Preámbulo de la Ley 3/2012 para justificar la supresión parcial de los salarios de tramitación carecen de la suficiente solidez para explicar la diferencia de trato creada por la norma. Si «el tiempo de duración del proceso judicial no parece un criterio adecuado para compensar el perjuicio que supone la pérdida del empleo», no lo será ni en el caso de que el empresario opte por la indemnización ni en el supuesto de readmisión y, sin embargo, solo se elimina el deber de abonar los salarios de trámite en el primer caso. Lo mismo se

${ }^{67}$ Sobre los antecedentes históricos de los salarios de tramitación puede consultarse GÁRATE CASTRO, F. J. (1994). Los salarios de tramitación. Un estudio de las percepciones salariales unidas a la declaración de improcedencia o nulidad del despido, Madrid, ACARL, pp. 85 y ss.; GORELLI HERNÁNDEZ, «La reforma laboral...», cit., pp. 288-289; LUJÁN ALCARAZ, J. y RÍOS MESTRE, J. M. ${ }^{a}$ (2004). «Despido y salarios de tramitación», en SEMPERE NAVARRO, A. V. (dir.), El despido: aspectos sustantivos y procesales, Cizur Menor (Navarra), Thomson/Aranzadi, pp. 598 y ss.

${ }^{68}$ Es por eso que se ha podido afirmar que la recuperación de los salarios dejados de percibir es «una lógica consecuencia de justicia» [MONTOYA MELGAR, A. (1992). «El despido improcedente y sus efectos», en AA. VV, Estudios sobre el despido disciplinario, 2. ${ }^{a}$ ed., Madrid, ACARL, p. 530].

69 Como se afirma en el recurso de los grupos parlamentarios: «el Tribunal parece obviar que esa posición dispar de los trabajadores, y de los empresarios, en uno y otro caso forma parte del tratamiento — respuesta - jurídico de una situación previa que sí es homogénea: la falta de justificación del despido de un trabajador, esto es, la calificación de ese despido como improcedente. $\mathrm{Y}$ es que, en realidad, las situaciones que deben ser enjuiciadas a efectos de constatar su homogeneidad son las que derivan de esa declaración de improcedencia (...) la comparación que realiza el Tribunal a efectos de determinar si existe o no homogeneidad se realiza demasiado «tarde», pues tiene lugar cuando ya se han delimitado, y por tanto diferenciado, las características de cada uno de los supuestos» (p. 83 del original). 
podría decir respecto del argumento de la socialización del coste o del que afirma que los salarios de tramitación actúan, en ocasiones, como un incentivo para estrategias procesales dilatorias ${ }^{70}$. Nada de ello explica el motivo por el que han de ser tratados de manera desigual dos trabajadores improcedentemente despedidos. La conclusión a la que se puede llegar es fácil: ninguno de estos argumentos expresan la verdadera finalidad perseguida por el legislador con la medida examinada. Su auténtico objetivo no es otro que facilitar el despido sin causa justificada del trabajador, contrario como es sabido a la Constitución, mediante la disminución de su coste para el empresario, en un argumento que aspira a conectar finalmente con la libertad de empresa del art. $38 \mathrm{CE}$. Sin embargo, si, como hemos sostenido aquí, la libertad de empresa no ampara ni el acto extintivo injustificado de la relación laboral, ni la concesión al empresario infractor de la opción, ni, por último, la validación de los efectos extintivos del acto inconstitucional, difícilmente podrá servir para justificar el trato desigual que estamos examinando.

La supresión de los salarios de tramitación en los casos vistos implica, por tanto, un paso adelante en el proceso de descausalización del despido, en perjuicio de la normatividad del derecho al trabajo ${ }^{71}$. Por un lado anima al empresario que desea despedir a un trabajador sin causa fundada a hacerlo, con tal que asuma el coste, cada vez más reducido, de la indemnización legalmente prescrita ${ }^{72}$. Los efectos de la medida dejan prácticamente desprotegidos frente al despido sin causa tanto a los trabajadores con escasa antigüedad como, fundamentalmente, a los trabajadores temporales, lo que tiene especial relevancia en un mercado de trabajo como el nuestro, caracterizado por una fuerte temporalidad ${ }^{73}$. El abono

${ }^{70}$ Una crítica de este argumento en TOROLLO GONZÁLEZ, F. J. (2012). «Despidos individuales (disciplinarios y por causas objetivas)», en MONTOYA MELGAR/GARCÍA MURCIA, op. cit., p. 242. El TC da por buena, sin embargo, la justificación del legislador en su Auto de 12 de febrero de 2014 [f.j. 6. A.a)].

71 Por todos, MOLERO, M. ${ }^{a}$ L. (2003). «Salarios de tramitación y régimen de despido». Aranzadi Social, núm. 2 (versión electrónica). Crítico con el desarrollo legislativo del principio causal, VALDÉS DAL-RÉ, F. (2001). «Itinerarios circulares del Derecho al Trabajo: del despido libre al despido indemnizado». Relaciones Laborales, núm. 11, Sección Editorial, tomo 1. Citado por la versión digital en pdf, que se puede consultar en laleydigital.es. Última visita: 27/05/2013.

72 Señalan este efecto incentivador, entre otros, GORELLI HERNÁNDEZ, «La reforma laboral...», cit., p. 288; LAHERA FORTEZA, J. (2003). «Los efectos de la reforma del despido», en GETE CASTILLO, P. y VALDÉS DAL-RÉ, F. (2003). Nuevo régimen jurídico del despido y del desempleo. Análisis crítico de la Ley 45/2002, Madrid, Cinca, p. 188; TOROLLO GONZÁLEZ, op. cit., p. 242. En contra, el ATC de 12 de febrero de 2014 afirma que esta posición «no deja de ser una presunción del órgano promotor» de la cuestión por él inadmitida [f.j. 6. A.c)].

73 En este sentido, LAHERA FORTEZA, «Los efectos...», cit., p. 193; MONEREO PÉREZ/ MOLINA NAVARRETE, op. cit., p. 333; GORELLI HERNÁNDEZ, «La reforma laboral...», cit., pp. 293-294; TOSCANI GIMÉNEZ, «Las reformas...» cit., p. 23. 
de la indemnización legal, cuyo cálculo se basa en el tiempo de servicio, queda como la única, exigua, barrera que le protege en el ejercicio de su derecho a la estabilidad en el empleo.

Por otra parte, la eliminación de los salarios de trámite dificulta en la práctica el desarrollo por los jueces de su labor de control de la causa del despido ${ }^{74}$. Si el empresario accede al abono de la indemnización legal el trabajador carece de incentivo alguno para el ejercicio de la acción judicial, a sabiendas de que una sentencia favorable únicamente va a suponer para él una victoria moral. Eso si no favorece, incluso, los pactos indemnizatorios a la baja, que pueden ser preferidos por el trabajador ante el efecto disuasorio del coste del proceso ${ }^{75}$.

En definitiva, la medida analizada discrimina al trabajador no readmitido, que se ve privado de su derecho a percibir los salarios de tramitación que deberían resultar para él de la extinción sin causa de la relación laboral a instancias de la empresa. Junto con la reducción de la indemnización por despido, culmina por el momento un proceso de descausalización del mismo que resulta contrario a las exigencias del derecho al trabajo del art. $35 \mathrm{CE}$.

\section{EL CONTROL JUDICIAL DE LAS CAUSAS DE DESPIDO COLECTIVO}

Otro de los motivos de inconstitucionalidad de la Ley 3/2012 alegados en el recurso de inconstitucionalidad de los grupos parlamentarios gira en torno a la definición legal de las causas del despido colectivo, extensibles también a la modalidad de despido por causas objetivas prevista en el apartado c) del art. $52 \mathrm{ET}^{76}$. La reforma de 2012 operó en este ámbito unos cambios tendentes a facilitar el recurso por el empresario a esta modalidad extintiva y, simultáneamente, a redu-

${ }^{74}$ Véase este argumente en, entre otros, BAYLOS/PÉREZ REY, op. cit., pp. 56-57; LAHERA FORTEZA, «Los efectos...», cit., p. 193; TOROLLO GONZÁLEZ, op. cit., p. 242; GÁRATE CASTRO, «La reforma...», cit., p. 133; o GORELLI HERNÁNDEZ, «La reforma laboral...», cit., p. 292. El vínculo de este aspecto con el derecho a la tutela judicial efectiva del art. 24.1 CE, en GÁRATE CASTRO, «La reforma...», cit., p. 133; o BAYLOS/PÉREZ REY, op. cit., p. 54. En este sentido, véase además el Voto Particular que formulan al ATC de 12 de febrero de 2014 los Magistrados Fernando Valdés Dal-Ré, Adela Asúa Batarrita y Luis Ignacio Ortega Álvarez, que sostiene en su fundamento 13 la condición de los salarios de tramitación como elemento de garantía del derecho a la tutela judicial efectiva.

75 Entre otros, GORELLI HERNÁNDEZ, «La reforma laboral...», cit., p. 292, LAHERA FORTEZA, «Los efectos...», cit., p. 187.

${ }^{76}$ Fundamento jurídico 7. 
cir el margen de decisión de los órganos judiciales en su labor de control de la legalidad de estos despidos. En este último sentido, afirma el Preámbulo que:

«La Ley se ciñe ahora a delimitar las causas económicas, técnicas, organizativas o productivas que justifican estos despidos, suprimiéndose otras referencias normativas que han venido introduciendo elementos de incertidumbre. (...) (T)ales referencias incorporaban proyecciones de futuro, de imposible prueba, y una valoración finalista de estos despidos, que ha venido dando lugar a que los tribunales realizasen, en numerosas ocasiones, juicios de oportunidad relativos a la gestión de la empresa. Ahora queda claro que el control judicial de estos despidos debe ceñirse a una valoración sobre la concurrencia de unos hechos: las causas.»

Los siguientes cuadros permiten comparar las diferencias existentes entre la redacción anterior del art. 51 ET y la introducida por la reforma laboral de 2012:

\begin{tabular}{|c|c|}
\hline Redacción Vigente & Redacción anterior a la Reforma 2012 \\
\hline $\begin{array}{l}\text { «Se entiende que concurren causas económi- } \\
\text { cas cuando de los resultados de la empresa se } \\
\text { desprenda una situación económica negati- } \\
\text { va, en casos tales como la existencia de pér- } \\
\text { didas actuales o previstas, o la disminución } \\
\text { persistente de su nivel de ingresos ordinarios } \\
\text { o ventas. En todo caso, se entenderá que la } \\
\text { disminución es persistente si durante tres } \\
\text { trimestres consecutivos el nivel de ingresos } \\
\text { ordinarios o ventas de cada trimestre es in- } \\
\text { ferior al registrado en el mismo trimestre del } \\
\text { ańo anterior.» }\end{array}$ & $\begin{array}{l}\text { Pérdidas o disminución de ingresos «que } \\
\text { puedan afectar a su viabilidad o a su capa- } \\
\text { cidad de mantener el volumen de empleo. A } \\
\text { estos efectos, la empresa tendrá que acreditar los } \\
\text { resultados alegados y justificar que de los mis- } \\
\text { mos se deduce la razonabilidad de la decisión } \\
\text { extintiva para preservar o favorecer su posición } \\
\text { competitiva en el mercado.» }\end{array}$ \\
\hline $\begin{array}{l}\text { «Se entiende que concurren causas técnicas } \\
\text { cuando se produzcan cambios, entre otros, } \\
\text { en el ámbito de los medios o instrumentos } \\
\text { de producción; causas organizativas cuando } \\
\text { se produzcan cambios, entre otros, en el } \\
\text { ámbito de los sistemas y métodos de traba- } \\
\text { jo del personal o en el modo de organizar } \\
\text { la producción y causas productivas cuando } \\
\text { se produzcan cambios, entre otros, en la } \\
\text { demanda de los productos o servicios que la } \\
\text { empresa pretende colocar en el mercado.» }\end{array}$ & $\begin{array}{l}\text { Causas técnicas, organizativas y producti- } \\
\text { vas: "(...) A estos efectos, la empresa deberá } \\
\text { acreditar la concurrencia de alguna de las } \\
\text { causas señaladas y justificar que de las mismas } \\
\text { se deduce la razonabilidad de la decisión } \\
\text { extintiva para contribuir a prevenir una } \\
\text { evolución negativa de la empresa o a mejorar } \\
\text { la situación de la misma a través de una más } \\
\text { adecuada organización de los recursos, que fa- } \\
\text { vorezca su posición competitiva en el mercado } \\
\text { o una mejor respuesta a las exigencias de la } \\
\text { demanda." }\end{array}$ \\
\hline
\end{tabular}

A juicio de los recurrentes, la redacción aprobada por la reforma de 2012 lesiona el derecho constitucional al trabajo, al prescindir del elemento de causalidad en 
la delimitación de los motivos económicos y empresariales para el despido, lo que implicaría, al mismo tiempo, una vulneración del derecho a la tutela judicial efectiva (art. 24.1 CE), en la medida en que impide el control judicial de su causa.

No cabe duda de que la tutela judicial en caso de despido se erige en aspecto básico de la protección del derecho al trabajo, tal y como se indica en la STC 20/1994 (f.j. 2):

«La reacción frente a la decisión unilateral del empresario prescindiendo de los servicios del trabajador, abstracción hecha del procedimiento para ello como factor formal de garantía y de las consecuencias que acarree legalmente, y en especial las económicas (indemnización), es uno de los aspectos básicos en la estructura de los derechos incluidos en ese precepto constitucional y a su vez se convierte en elemento condicionante para el pleno ejercicio de los demás de la misma naturaleza, como el de huelga o de sindicación e incluso del que garantiza la tutela judicial efectiva (SSTC 7/1993 y 14/1993). En efecto, la inexistencia de una reacción adecuada contra el despido o cese debilitaría peligrosamente la consistencia del derecho al trabajo y vaciaría al Derecho que lo regula de su función tuitiva, dentro del ámbito de lo social como característica esencial del Estado de Derecho (art. 1 C. E.), cuya finalidad en este sector no es otra que compensar la desigualdad de las situaciones reales de empresario y trabajador a la hora de establecer las condiciones o el contenido de esa relación mutua o sinalagmática, máxime si ello acontece a título individual y no colectivo (SSTC 123/1992, 98/1993 y 177/1993). Estas reflexiones reconducen el discurso a la igualdad efectiva, traída a cuento en un principio».

Por este motivo, una norma que impidiera el control judicial de fondo del ajuste a la ley y a la Constitución de un determinado tipo de despido sería inconstitucional, por ir en contra del derecho al trabajo del art. 35 CE y del derecho a la tutela judicial efectiva. Sometido a su consideración un despido, el órgano judicial debe poder realizar en torno a él el mismo examen de proporcionalidad que se debe realizar de todo límite de un derecho constitucional ${ }^{77}$. Ningún ras-

77 Para un sector de la doctrina, la ley no descarta este examen de proporcionalidad. En este sentido, LAHERA FORTEZA, «Medidas en contratación...», cit., p. 7; MOLINA NAVARRETE, «La versión parlamentaria...», cit., pp. 23, 72-74 y 81; RODRÍGUEZ-PIÑERO Y BRAVO FERRER, M. (2012). «Flexibilidad interna y externa en el Real Decreto-Ley 3/2012». Diario La Ley, núm. 7833, Sección Doctrina, año XXXIII, ref. D-144, p. 8 (citado por la edición digital en pdf, obtenida de laleydigital.es. Última visita 27/05/2013); MIÑARRO YANINI, op. cit., pp. 13 y ss.; APARICIO TOVAR, J. (2012). «Las causas del despido basadas en necesidades de funcionamiento de la empresa». Revista de Derecho Social, núm. 57, p. 163; GOÑI SEIN, J. L. (2012). «El nuevo modelo normativo de despido colectivo implantado por la Ley de Reforma Laboral de 2012». Documentación Laboral. Revista de relaciones laborales, economía y sociología del trabajo, y trabajo autónomo, núms. 95-96, p. 33; MONEREO PÉREZ, J. L. (2012). 
go distintivo concurre en el derecho con el que entra en conflicto, la libertad de empresa, que obligue a una excepción en este punto $^{78}$. A la posibilidad de realizar este examen judicial de la necesidad del despido se ha opuesto que dicho juicio supone una inaceptable intromisión por los tribunales en decisiones relativas a la gestión de la empresa que han de corresponder al empresario, en virtud del derecho del art. $38 \mathrm{CE}^{79}$. Sin embargo, esta oposición constituye un acercamiento al problema planteado desde una perspectiva unilateral coincidente con la libertad de empresa e ignora, con ello, la concurrencia del otro término del conflicto jurídico planteado: el derecho al trabajo ${ }^{80}$.

Como afirma el TC:

«(L)a declaración de procedencia del despido podría afectar a la libertad de trabajo comprendida en el derecho al trabajo que reconoce el art. 35.1 CE (...). (E)n situaciones como la expuesta, el canon propio del art. 24.1 CE no se ciñe únicamente a la comprobación negativa de que la decisión judicial no es infundada, manifiestamente irrazonable o arbitraria ni incurre en error patente (...), sino que añade a ese control el positivo sobre la ponderación y adecuación de la

«El régimen jurídico de los despidos colectivos después de la reforma de 2012». Temas Laborales. Revista Andaluza de Trabajo y Bienestar Social, núm. 115, Monográfico sobre la Reforma Laboral de 2012, pp. 324-325. En contra, GIL PLANA, J. (2012). «Despido colectivo: aspectos sustantivos», en MONTOYA MELGAR/GARCÍA MURCIA, op. cit., pp. 262, 265-266. Cfr. un control limitado a los criterios de adecuación y proporcionalidad en sentido estricto de la causa, en BLASCO PELLICER, A. (2013). La extinción del contrato de trabajo en la reforma laboral de 2012, Valencia, Tirant lo Blanch, pp. 33-34. Parte de los autores señala como vía de entrada del control de proporcionalidad las referencias al dolo, fraude de ley o abuso de derecho. Así, CASAS BAAMONDE/RODRÍGUEZ-PIÑERO Y BRAVO FERRER/VALDÉS DAL-RÉ, $o p$. cit., p. 31; ALFONSO MELLADO, C. L. (2012). «Reforma laboral y ley reguladora de la jurisdicción social». Revista de Derecho Social, núm. 57, p. 267 o, en términos de subsidiariedad, LAHERA FORTEZA, J. (2012). «Expedientes de regulación de empleo extintivos, suspensivos y de reducción de jornada», en, del mismo autor (coord.), Reforma Laboral 2012: preguntas y respuestas, Madrid, Ediciones Cinca, 2012, p. 96. En contra de este proceder, MOLINA NAVARRETE, «La versión...», cit., p. 23.

${ }^{78}$ De hecho, la doctrina no duda en aplicar el examen de proporcionalidad a los límites de la libertad de empresa. En este sentido, SAGARDOY BENGOECHEA, op. cit., pp. 366 y ss.; PAZARES/ALFARO ÁGUILA-REAL, op. cit., p. 409.

79 Así, se ha señalado que «cuando el juez entra a valorar en cuanto al fondo la decisión empresarial, se está haciendo que asuma o se invista del papel del empresario» (DURÁN LÓPEZ, op. cit., p. 66).

80 Advierte contra la adopción de una visión unilateral del conflicto, BAYLOS/PÉREZ REY, op. cit., p. 99. En opinión de GOERLICH PESET, dentro del marco constitucional el legislador puede disponer distintas soluciones al respecto, de manera que cada una de ellas refleja un distinto nivel de intensidad en la protección de la libertad de empresa («Libertad de empresa...», cit., pp. 254-255). 
motivación de tal decisión judicial, que necesariamente ha de exteriorizarse (...) a los derechos concernidos» (STC 192/2003, f.j. 3).

Así, en particular, el juez debe controlar:

a. Que el despido es adecuado para la protección de otro bien o derecho constitucionalmente reconocido, que en este caso será la libertad de empresa ${ }^{81}$. Ahora bien, como se ha sostenido con anterioridad, el derecho del art. $38 \mathrm{CE}$ no permite el despido libre de los trabajadores. El despido, en tanto que límite a un derecho constitucional, no puede ser un fin en sí mismo, sino solo un medio para conseguir un objetivo. Se trata, pues, más bien, de que bajo el amparo de la libertad de empresa su titular adopta, a la vista de las circunstancias concurrentes, una decisión de naturaleza económica, organizativa, técnica o relativa a la producción cuya ejecución requiere o justifica el despido de personal.

b. Que el acto extintivo sea necesario, esto es, que manifiestamente no exista un modo alternativo de conseguir el fin pretendido, con la misma intensidad que se logra con el despido, pero con un coste menor para el derecho al trabajo ${ }^{82}$.

El examen de la necesidad de la medida es imprescindible para que bajo el argumento de la libertad de empresa no queden protegidas decisiones arbitrarias del empresario, toda vez que, cuando existe manifiestamente un modo alternativo de conseguir el objetivo alegado con la misma eficacia, los intereses protegibles del empresario no sufren ningún menoscabo por el mero hecho de exigirle el recurso al medio alternativo. El órgano judicial deberá procurar, para no lesionar por su parte la libertad de empresa, no excederse en su labor de control en relación con los términos aquí planteados ${ }^{83}$.

c. Que existe una relación de proporcionalidad en sentido estricto entre el daño que en términos constitucionales produce la decisión extintiva y los beneficios que de ella se derivan para los intereses de la empresa, que pueden encontrar su amparo en los arts. 38 y $33 \mathrm{CE}^{84}$. En este sentido, el órgano judicial ha de poder declarar la ilicitud del despido claramente carente de medida en relación con el fin perseguido. Así, por ejemplo, no cabe duda de que la libertad de empresa se encuentra en una situación relativamente débil frente al derecho al trabajo cuando el despido se basa en una disminución irrelevante del nivel de ingresos, o más aún de ventas con mantenimiento de estos, en el marco de una

\footnotetext{
81 En este sentido, MIÑARRO YANINI, op. cit., p. 15; GOÑI SEIN, op. cit., p. 38.

82 Cfr. BAYLOS/PÉREZ REY, op. cit., p. 96-97.

83 Véase esta advertencia en GOERLICH PESET, «Libertad de empresa...», cit., pp. 252-253.

84 Sobre este examen de proporcionalidad en sentido estricto, GOÑI SEIN, op. cit., p. 38.
} 
situación económica global saneada de la empresa ${ }^{85}$. Desde un punto de vista constitucional, los fines no justifican siempre los medios.

La pregunta que debemos formularnos es si la regulación actualmente vigente del art. 51.1 ET impide al órgano judicial realizar una labor de control con estas características. La respuesta, a nuestro juicio, ha de ser negativa. Ocurriría esto si la norma obligara a la declaración automática de procedencia del despido con tal que el empresario acreditara la concurrencia de cualquier circunstancia económica, técnica, organizativa o productiva de las que caben en el tenor literal del precepto ${ }^{86}$. Tal conclusión es, sin embargo, insostenible, cualquiera que sea la intención que tuviera el legislador. Todas las normas deben ser interpretadas de acuerdo con la Constitución. Ciertamente, la definición de las causas de despido colectivo realizada por la Ley es sumamente genérica, pero esto no es determinante de su inconstitucionalidad. El despido colectivo continúa teniendo carácter causal ${ }^{87}$. De otro modo, idéntico camino deberían seguir otras causas de despido de amplio significado legalmente previstas, tales como la transgresión de la buena fe contractual [art. 54.2.d) ET]. La indeterminación de las causas amplía en este caso el margen de decisión del órgano judicial, no lo excluye, de manera que nada condiciona su sujeción a la Constitución.

En definitiva, una circunstancia económica, técnica, organizativa o de producción solo puede considerarse, desde un punto de vista constitucional, «causa» de un despido en el sentido del art. 51 ET, cuando lo justifica como una decisión adecuada, necesaria y proporcional respecto de la protección de los intereses legítimos de la empresa. El precepto admite, por tanto, una interpretación acorde con la Constitución.

\section{REFLEXIÓN FINAL}

El derecho al trabajo es un derecho constitucional. Posiblemente, una frase con un contenido tan obvio no sea el mejor modo de dar por concluido

${ }^{85}$ Como se ha afirmado, «es claro que según la norma puede haber situación económica negativa sin pérdidas, pero eso obligará a un análisis más riguroso a la hora de su control» (APARICIO TOVAR, op.cit, p. 158). La posibilidad de que empresas en una situación económica saneada acudan al despido colectivo, en TOSCANI GIMÉNEZ, «Las reformas...», p. 10; GORELLI HERNÁNDEZ, «La reforma laboral...», cit., p. 297. En contra, GOÑI SEIN, op. cit., p. 32.

${ }^{86}$ Una interpretación de la ley limitadora de las facultades judiciales en el sentido indicado puede verse en TOSCANI GIMÉNEZ, «Las reformas...», cit., p. 10.

87 CASAS BAAMONDE/RODRÍGUEZ-PIÑERO Y BRAVO-FERRER/VALDÉS DALRÉ, op. cit., p. 31; RODRÍGUEZ-PIÑERO Y BRAVO-FERRER, «Flexibilidad interna...», cit., p. 9; MIÑARRO YANINI, op. cit., pp. 7-8; ALFONSO MELLADO, op. cit., p. 267. 
un artículo doctrinal, pero dado el estado de las cosas bien se puede finalizar recordando lo que tendría que ser el principio, y al principio está la Constitución.

El desarrollo normativo de un conflicto entre derechos constitucionales, en este caso derecho al trabajo y libertad de empresa, cuando, como sucede en la reforma de 2012, viene orientado unilateralmente por uno de ellos, sería un terreno abonado para sospechas de inconstitucionalidad en el marco de cualquier coyuntura social y económica distinta de la actual. A pesar del evidente peso de este factor, conviene insistir en que el régimen jurídico de las relaciones laborales no puede depender exclusivamente de la situación económica del país, de las presiones de los mercados o de las exigencias que se derivan de una competencia feroz en un mundo globalizado. Estas son circunstancias que han de ser tenidas en cuenta por el legislador a la hora de adoptar las decisiones que sean necesarias, pero dentro del marco de posibilidades que erige el texto constitucional.

Los recursos de inconstitucionalidad presentados contra la Ley 3/2012 sitúan al Tribunal Constitucional ante el reto de desarrollar la jurisprudencia existente sobre el derecho al trabajo, hasta el momento tan escasa como concluyente. La opción de dar continuidad a su primera doctrina implicaría un elevado riesgo para la permanencia de la norma en el ordenamiento. Sin embargo, existe también la posibilidad de que se opte por someterla a una importante reelaboración para dar cabida a la norma recurrida. Será entonces el momento de analizar qué queda del ya suficientemente maltratado derecho al trabajo.

Title:

THE RIGHT TO WORK UNDER THE LABOUR REFORM OF 2012. A CONSTITUTIONAL APPROACH

\section{Summary:}

1. Introduction 2. The right to work and the freedom of enterprise 3. The right to work and the free termination of the employment relationship during its first year 3.1. Initial approach 3.2. The constitutionality of the one-year trial period 3.3. The employer's right to terminate the contract during its first year 4 . The stimulus for the hiring of persons receiving unemployment benefits and the equal access to employment. 5. Critical study of regulation of unfair dismissal and procedural salary from a constitutional perspective 5.1. Initial approach 5.2. The unfair dismissal: a constitutional analysis 5.3. The Constitution and the denial of the procedural salary 6. Judicial review in cases of collective dismissal. 7. Final reflections 


\title{
Resumen:
}

La reforma laboral de 2012 ha suscitado importantes cuestiones acerca del régimen jurídico del derecho al trabajo. Así, en este artículo se sostiene que la introducción de una modalidad contractual que concede al empresario la potestad de resolver libremente el contrato laboral durante el primer año supone, ya sea concebido este plazo como periodo de prueba o como medio para el fomento de un empleo estable, una vulneración del derecho del trabajador a la estabilidad en el empleo, reconocido como manifestación del art. 35 CE por el Tribunal Constitucional. También se analiza desde una perspectiva constitucional el régimen jurídico del despido improcedente, que consideramos incoherente con la condición del derecho al trabajo como derecho fundamental. Finalmente, sostenemos que la configuración legal dada a las causas del despido colectivo no puede llegar a impedir su control judicial desde la perspectiva del principio de proporcionalidad, ya que este se presenta como una exigencia derivada del propio derecho al trabajo y del derecho a la tutela judicial efectiva.

\begin{abstract}
:
The 2012 labour reform has raised important questions regarding regulation of the right to work. This paper proposes that the employer's right to terminate a contract in support of entrepreneurs during its first year, interpreted either as a probationary period or as a measure for the promotion of stable employment, violates the constitutional right of every worker to stability in employment (Article 35 of the Constitution). Furthermore, regulation of unfair dismissal is analyzed from a constitutional perspective to reach the conclusion that it is incompatible with the constitutional right to work. Finally, it is argued that the regulation of the causes of collective dismissal cannot prevent the Constitutional Court from reviewing whether the principle of proportionality has been observed, since this is a requirement arising from the constitutional rights to work and to an effective judicial protection.
\end{abstract}

\section{Palabras clave:}

Derecho al trabajo, libertad de empresa, despido, igualdad de oportunidades en el acceso a la contratación.

\section{Key words:}

Right to work, freedom of enterprise, regulation of dismissal, equal opportunities in hiring. 
